\title{
Characteristics of the Onset, Withdrawal, and Breaks of the Western North Pacific Summer Monsoon in the 1949-2014 Period
}

\author{
InMACUlada Vega, Pedro Ribera, AND DAVID Gallego \\ Departamento de Sistemas Físicos, Químicos y Naturales, Universidad Pablo de Olavide, Sevilla, Spain
}

(Manuscript received 28 September 2019, in final form 5 June 2020)

\begin{abstract}
The western North Pacific summer monsoon (WNPSM) onset and withdrawal dates as well as its breaks have been determined throughout the 1949-2014 period by defining the monsoon daily directional index (MDDI). This index, developed exclusively with wind direction observations, is an upgrade of the monthly western North Pacific directional index. The onset date shows a high interannual variability, varying between early May and early August, whereas the WNPSM withdrawal shows a lower interannual variability, occurring between October and mid-November. The MDDI reflects the multibreak character of the WNPSM. Breaks, which tend to last a few weeks, are more likely to happen from mid-August to early September and from late June to mid-July. This bimodal distribution shows decadal variability. In addition, the monsoon dates determined by the MDDI show very good agreement with relationships previously described in literature, such as the influence of tropical Pacific SST on the monsoon onset/withdrawal and changes in tropical cyclone (TC) tracks related to monsoon breaks. The WNPSM tends to start earlier (later) and finish later (earlier) under eastern Pacific (EP) La Niña (El Niño) conditions, especially from the 1980s on. Central Pacific (CP) ENSO is also associated with the monsoon withdrawal, which is advanced (delayed) under CP El Niño (La Niña). TCs tend to move from the Philippine Sea to the South China Sea during active monsoon days whereas they tend to reach higher latitudes during inactive monsoon days, especially in August and July.
\end{abstract}

\section{Introduction}

Monsoons are associated with a seasonal reversal of the dominant wind direction and a wet season that generally starts in low latitudes, advances northward/eastward, and then retreats backward (e.g., Wang and LinHo 2002). This phenomenon strongly affects agriculture in Asia, which is the livelihood of millions of people (Wang 2006; Prasanna 2014). In particular, sowing dates and both crop duration and crop yield depend on the monsoon onset and intensity (Prasanna 2014; Tao et al. 2004; Wang 2006, chapter 18; Lansigan et al. 2000). Therefore, it is important to have the best possible characterization of the monsoon dates, such as the onset and withdrawal.

Asia is particularly interesting because it is influenced by the Indian summer monsoon (ISM), east Asian summer monsoon (EASM), and western North Pacific summer monsoon (WNPSM). In this paper we focus on the less studied one, the WNPSM. The core of this monsoon is located at $10^{\circ}-20^{\circ} \mathrm{N}, 110^{\circ}-160^{\circ} \mathrm{E}$ (Murakami and Matsumoto 1994) although Wang et al. (2001) found

\footnotetext{
Corresponding author: Inmaculada Vega, ivegmar@upo.es
}

the regions $5^{\circ}-15^{\circ} \mathrm{N}, 100^{\circ}-130^{\circ} \mathrm{E}$ and $20^{\circ}-30^{\circ} \mathrm{N}, 110^{\circ}-$ $140^{\circ} \mathrm{E}$ [domains 1 and 2 (D1 and D2), respectively, in Fig. 1] to be best representative of the synoptic-scale monsoon circulation. Figure 1 shows the average surface winds and land precipitation in this region during the core of the monsoon season (July-August). The Somali jet (Findlater 1969) and the cross-equatorial flow from the western Pacific Ocean converge at around $6^{\circ} \mathrm{N}$, resulting in southwesterly winds over D1. At higher latitudes, the atmospheric circulation is dominated by the North Pacific high, with southeasterly winds in D2. The precipitation related with the WNPSM circulation (shading) is concentrated over south China, the Indochina Peninsula, and the Philippines.

Currently, there is not a consensus about how to determine the onset and withdrawal dates of a monsoon. Variables such as rainfall (e.g., Wang and LinHo 2002; Janowiak and Xie 2003; Tomita et al. 2013), outgoing longwave radiation (OLR; Wu and Wang 2000; Wu et al. 2009; Xu and Lu 2015), wind (Chang and Chen 1995; Wang et al. 2004; Luo and Lin 2017), precipitable water (Zeng and Lu 2004), or a combination of them (Wang and Wu 1997; Xie et al. 1998; Zhang 2010) have been 


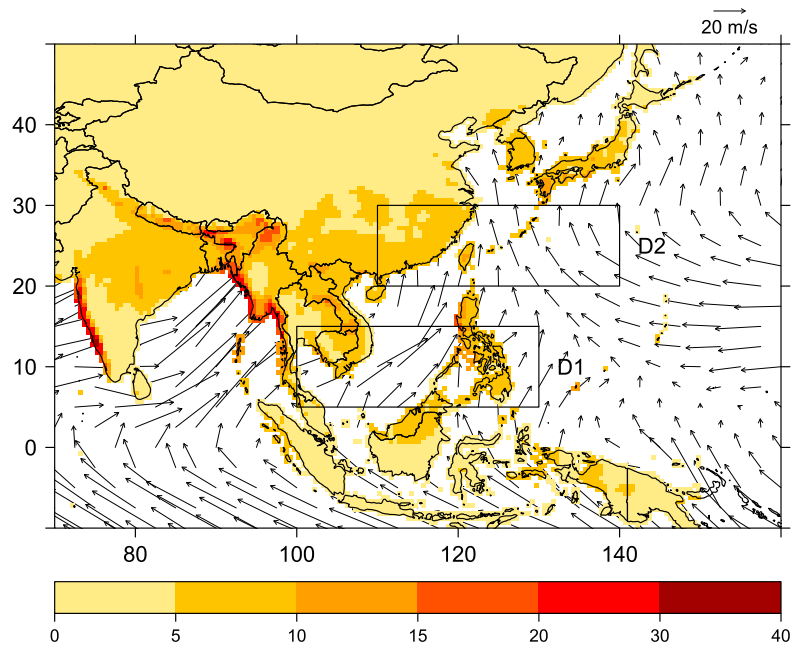

FIG. 1. Composites of daily land precipitation (shading; $\mathrm{mm}$ day $^{-1}$ ) and wind at $\sigma=0.995$ (arrows; $\mathrm{m} \mathrm{s}^{-1}$ ) for July-August throughout the 1951-2007 period. Black rectangles (D1 and D2) correspond to the regions where the WNPDI (Vega et al. 2018) is computed.

used to establish the beginning and the end of the monsoon season over the western North Pacific. However, abrupt changes in those variables are not necessarily concurrent and, therefore, discrepancies related to monsoon dates might be found among previous studies (Murakami and Matsumoto 1994; Wang and LinHo 2002; Zeng and Lu 2004; He et al. 2017).

As the WNPSM circulation covers a vast oceanic area (Murakami and Matsumoto 1994), the beginning and end of the WNPSM-related precipitation has large variations within its domain (multistage onset; $\mathrm{Wu}$ and Wang 2001; Wu 2002). Monsoonal rains start over the South China Sea around mid-May, progress northeastward passing through the Philippines in mid-June, and reach the Mariana Islands around mid-July ( $\mathrm{Wu}$ and Wang 2000, 2001; Wang and LinHo 2002). Similarly, the retreat of the WNPSM starts around September in the easternmost part of the region and finishes in November over the South China Sea (Wang and LinHo 2002; Janowiak and Xie 2003; Zeng and Lu 2004). Furthermore, monsoon onset has a large interannual variability at local scale (Murakami and Matsumoto 1994; Wu and Wang 2000), related to the interannual variability of the intraseasonal oscillations (ISO; Kajikawa and Wang 2012; He et al. 2017) and the seasonal cycle (Wu and Wang 2000). The former is dominant over India whereas the latter plays a major role in the easternmost part of the WNPSM domain. In particular, the variability of the seasonal cycle in that region is associated with the great variation of tropical eastern Pacific SST (Wu and Wang 2000). Regarding eastern Pacific (EP) ENSO, the monsoon onset tends to be delayed (advanced) in El Niño (La
Niña) years (Wu and Wang 2000; Zhang 2010; Zhou and Chan 2007; Xie et al. 1998; Tanaka 1997). Along this line, Zhang (2010) and Luo and Lin (2017) suggested that El Niño (La Niña) might advance (delay) the retreat of the monsoon in the South China Sea.

The WNPSM evolution, which can alternate active and inactive spells, is largely due to the ISO modes of 10-20 and 30-60 days (Wang and $\mathrm{Xu} 1997 ; \mathrm{Xu}$ and $\mathrm{Lu}$ 2015; Guan and Chan 2006). The relevance of each mode varies yearly (Mao and Chan 2005). Inactive spells (breaks) are particularly interesting as they imply a reduction in precipitation, convection suppression (e.g., Krishnamurthy and Shukla 2007; Xu and Lu 2015), and anomalous circulation at lower troposphere (e.g., Gadgil and Joseph 2003). This phenomenon has been extensively studied for the ISM (Gadgil and Joseph 2003; Joseph and Simon 2005; Rajeevan et al. 2010), whereas it has only recently been addressed for the WNPSM (Xu and $\mathrm{Lu} 2015$, 2018), after the pioneering studies of Wang and $\mathrm{Wu}(1997)$ and Wang and $\mathrm{Xu}$ (1997). Similar to the monsoon onset, there is not an extended objective criterion to define a monsoon break. It is common to use precipitation data (Gadgil and Joseph 2003; Rajeevan et al. 2010) or OLR (Xu and $\mathrm{Lu} 2015$ ) to determine break spells, although zonal wind can be considered as well (Joseph and Simon 2005). Depending on the definition, the annual number of monsoon breaks as well as their date and duration might vary. For instance, monsoon break definitions based on precipitation or OLR tend to set break spells lasting around 5 days (Gadgil and Joseph 2003; Xu and Lu 2015), whereas that duration might vary between one to three weeks when considering zonal wind (Joseph and Simon 2005). Regarding the WNPSM, Wang and Xu (1997) identified two climatological breaks, 10-14 July and 3-7 September, over the Philippines. Furthermore, Xu and Lu (2018) revealed a decadal change of the break in the easternmost part of the WNPSM domain.

On the other hand, the western North Pacific has high tropical cyclone (TC) activity (Lander 1996; He et al. 2015; Choi et al. 2016; Li and Zhou 2018), which affects the population and economy of countries nearby (Ribera et al. 2008; Zhang et al. 2009; Pan et al. 2010; Li and Zhou 2018; Sun et al. 2018). That activity is modulated by the WNPSM. In particular, the WNPSM trough favors TC development (Chen et al. 2004; Cao et al. 2014; Zong and $\mathrm{Wu}$ 2015). Furthermore, TC trajectories are modulated by the WNPSM phases (Wang and Wu 1997; Xu and Lu 2016), intensity (Choi et al. 2016), and trough orientation (Lander 1996). In this sense, Wang and Wu (1997) found differences in TC course along the four cycles, including dry and wet phases, which they considered for the WNPSM (Table 1). For instance, during their dry phase 
TABLE 1. Date of each cycle of the WNPSM and their wet and dry phases, according to Wang and Wu (1997).

\begin{tabular}{llll}
\hline \hline Cycle & \multicolumn{1}{c}{ Date } & Wet phase & \multicolumn{1}{c}{ Dry phase } \\
\hline I & 11 May-14 Jun & 16-25 May & 31 May-9 Jun \\
II & 15 Jun-24 Jul & 15-24 Jun & 5-14 Jul \\
III & 4 Aug-17 Sep & 14-23 Aug & 29 Aug-7 Sep \\
IV & 3 Oct-20 Nov & 13-22 Oct & 2-11 Nov
\end{tabular}

TC tracks between the Philippines Sea and the South China Sea were more zonal and an increase of TC was observed northeastward from the Mariana Islands. In this regard, $\mathrm{Xu}$ and $\mathrm{Lu}$ (2016) found an increase (decrease) of TC to the east of the Mariana Islands (to the southeast of Japan) during their climatological break in early August.

From the previous paragraphs, it is evident that the WNPSM main dates, and their impacts, are extraordinarily difficult to characterize. The objective of this paper is to develop a new index capable of capturing the general imprint of the WNPSM circulation in the wind field, for as long as possible, to study the long-term variability in its onset, withdrawal, and breaks. This index is based on the one recently developed by Vega et al. (2018) that showed that in situ measurements of wind direction taken aboard ships could be used to evaluate the WNPSM intensity. However, the limited resolution of their approach missed some important details of the WNPSM such as the onset and withdrawal dates and the intraseasonal variability.

\section{Data and methodology}

\section{a. Data}

Wind direction observations were taken from the International Comprehensive Ocean and Atmospheric Dataset (ICOADS; Freeman et al. 2017), whose most recent release (3.0) holds over 456 million individual observations covering the period 1662-2014. For this study we used the raw (i.e., not gridded) database.

The traditional ENSO was quantified by the Niño-3 index (EN3), defined as the SST anomalies averaged over the region $5^{\circ} \mathrm{S}-5^{\circ} \mathrm{N}, 210^{\circ}-270^{\circ} \mathrm{E}$. Following Ashok et al. (2007), we defined $\mathrm{El}$ Niño Modoki index as EMI $=\mathrm{SSTA}_{\mathrm{C}}-$ $0.5 \times \mathrm{SSTA}_{\mathrm{E}}-0.5 \times \mathrm{SSTA}_{\mathrm{W}}$. The subscripts C, E, and W correspond, respectively, to the regions $10^{\circ} \mathrm{S}-10^{\circ} \mathrm{N}, 165^{\circ}-$ $220^{\circ} \mathrm{E} ; 15^{\circ} \mathrm{S}-5^{\circ} \mathrm{N}, 250^{\circ}-290^{\circ} \mathrm{E}$; and $10^{\circ} \mathrm{S}-20^{\circ} \mathrm{N}, 125^{\circ}-145^{\circ} \mathrm{E}$, where the SST anomalies (SSTA) were averaged. Both indices were computed with the monthly $1^{\circ} \times 1^{\circ}$ gridded Centennial in situ Observations-Based Estimates of SST (COBE; Hirahara et al. 2014) dataset. SST data were previously detrended at each grid point by a linear regression with 1900-2013 as the base period. From now on, we use EP ENSO and CP ENSO (central Pacific ENSO) to refer to "traditional" ENSO and ENSO Modoki, respectively.
Daily land precipitation data, gridded at $0.5^{\circ} \times 0.5^{\circ}$, for the 1951-2007 period were taken from the APHRODITE (Asian Precipitation-Highly Resolved Observational Data Integration Towards Evaluation of Water Resources) dataset (Yatagai et al. 2012). We also used daily vertical velocity at $500 \mathrm{hPa}$, SLP, and wind at $\sigma=0.995$ level, gridded at $2.5^{\circ} \times 2.5^{\circ}$, for the period 1949-2013 from the NCEP-NCAR Reanalysis (Kalnay et al. 1996).

TC data over the WNP were taken from the Joint Typhoon Warning Center (JTWC; http://www.metoc. navy.mil/jtwc/jtwc.html?western-pacific) for the 19492013 period. The distribution of $\mathrm{TC}$, at $5^{\circ} \times 5^{\circ}$ spatial resolution, was estimated by counting the number of TCs in each grid point over the $0^{\circ}-50^{\circ} \mathrm{N}, 90^{\circ}-180^{\circ} \mathrm{E}$ region. Although the TC data were available at $6-\mathrm{h}$ intervals $(0000,0600,1200$, and 1800 UTC), a TC was counted only once per day even if it remained in the same box more than $6 \mathrm{~h}$ during that particular day.

Daily values on 29 February in leap years were excluded from all subsequent analysis. To test the statistical significance of composited differences, a Monte Carlo test was carried out.

\section{b. Methodology}

The monthly index originally developed by Vega et al. (2018) for the WNPSM, the western North Pacific directional index (WNPDI), was defined as the sum of the percentage of days in a month with wind blowing from the west in the D1 area and the corresponding percentage from the east within D2 (see Fig. 1). A westerly (easterly) day is defined when a minimum of $39 \%$ (46\%) of the total number of observations available for a given day at D1 (D2) corresponds to winds blowing between $225^{\circ}$ and $315^{\circ}\left(45^{\circ}\right.$ and $\left.135^{\circ}\right)$ from the true north. These percentages resulted from a calibration procedure aimed to maximize the correlation of the WNPDI with the classical index, defined by Wang et al. (2001), to quantify the strength of the WNPSM [see Vega et al. (2018) for further details]. Directional indices tend to be scarcely sensitive to changes in these thresholds. For the daily index developed in this paper, we have checked that variations of up to $\pm 10 \%( \pm 5 \%)$ in the values of these thresholds produce indices almost identical to the optimal case, with Pearson correlation coefficients higher than $r=$ 0.95 (0.98) with $p<0.01$ in both cases (figure not shown).

Figure 2 illustrates the evolution of the daily number of wind direction observations stored on ICOADS at D1 and D2 between 1800 and 2014. Observations are quite sparse in both regions before the mid-1850s but they increase afterward, being available almost continuously on a daily basis from the first decade of the twentieth century, except during World War II. Between the 1920s and the 1940s a very significant growth in data density is found, with a 


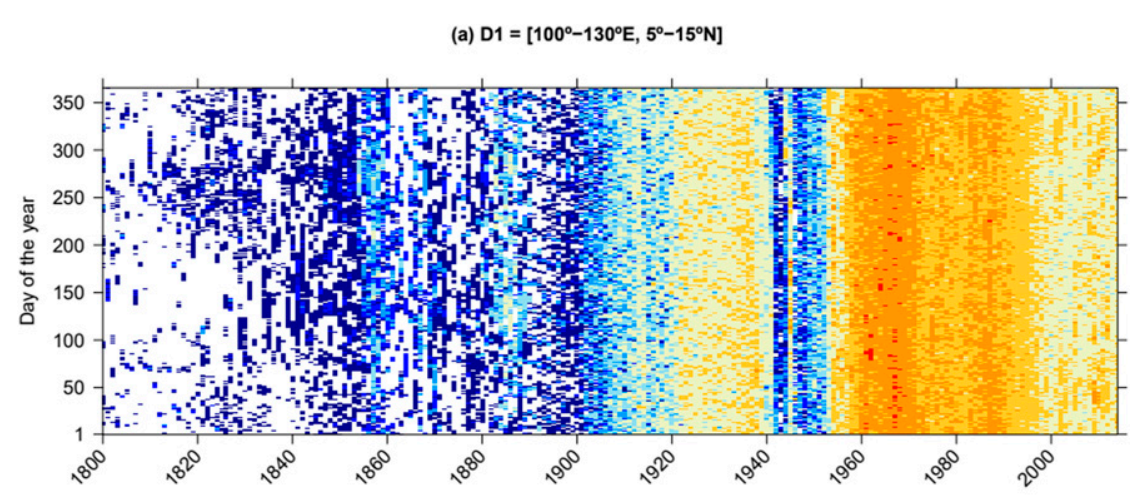

(b) $\mathrm{D} 2=\left[110^{\circ}-140^{\circ} \mathrm{E}, 20^{\circ}-30^{\circ} \mathrm{N}\right]$

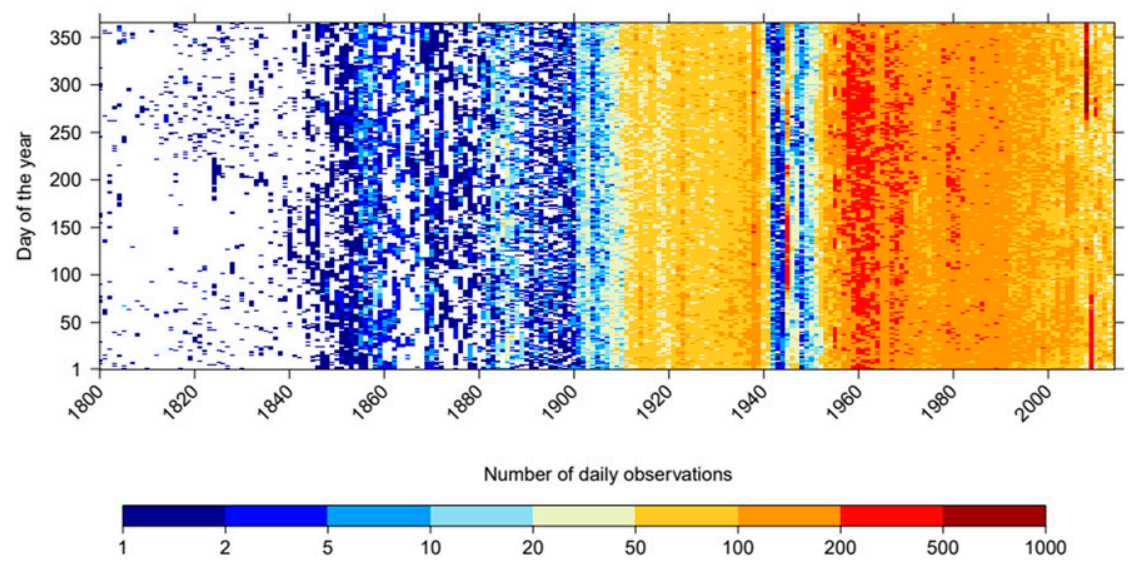

FIG. 2. Number of daily wind direction observations in ICOADS at (a) D1 $\left(5^{\circ}-15^{\circ} \mathrm{N}, 100^{\circ}-\right.$ $\left.130^{\circ} \mathrm{E}\right)$ and (b) $\mathrm{D} 2\left(20^{\circ}-30^{\circ} \mathrm{N}, 110^{\circ}-140^{\circ} \mathrm{E}\right)$ for the period $1800-2014$.

typical number of daily raw observations between 10 and 100 at D1 and between 50 and 200 at D2. After the dramatic decrease during World War II, a new increase in data availability is detected, with more than 100 daily observations at D1 and more than 200 at D2. In this regard, Gallego et al. (2015) showed that the uncertainty of an index based on wind direction persistence, which critically depends on the number of available observations, falls well below $\pm 10 \%$ of its optimal value when 10 or more observations per day are available. The increase in data availability in D1 and D2 since the late 1940s evidenced in Fig. 2 strongly suggests that it is possible to develop a daily directional index starting after World War II. In this research, we selected the period 1949-2014 to develop a new version of the WNPDI at daily scale because it is also possible to validate it against daily precipitation series.

\section{1) Definition of THE DAILY WESTERN NORTH PACIFIC DIRECTIONAL INDEX}

The western North Pacific monsoon daily directional index (MDDI) is defined for a particular day $d$ as the sum of the proportion of days with prevailing wind blowing from the west at D1 $\left(n_{\mathrm{W}, \mathrm{D} 1} / n_{1}\right)$ and from the east at $\mathrm{D} 2\left(n_{\mathrm{E}, \mathrm{D} 2} / n_{2}\right)$ considering a window of 21 days centered at that day $d$ and expressed as a percentage [Eq. (1)]. The terms $n_{1}$ and $n_{2}$ correspond to the number of days with observations over D1 and D2, respectively, within the sliding window. This window width represents a compromise between computing the index with an enough number of observations and capturing the highest possible frequency fluctuations of the wind flux. The criteria followed to define a day with wind blowing from the west (east) are the same as those followed in Vega et al. (2018). Furthermore, a minimum of 10 days within the sliding window was required to have at least four daily observations in each domain. This implies a minimum of 80 observations within the temporal window to compute each daily value of the index.

$$
\mathrm{MDDI}_{d}=\left(\frac{n_{\mathrm{W}, \mathrm{D} 1}}{n_{1}}+\frac{n_{\mathrm{E}, \mathrm{D} 2}}{n_{2}}\right)_{d-10: d+10} \times 100 .
$$

Figure 3 shows the mean annual distribution of the sodefined MDDI for the 1949-2014 period. During boreal 


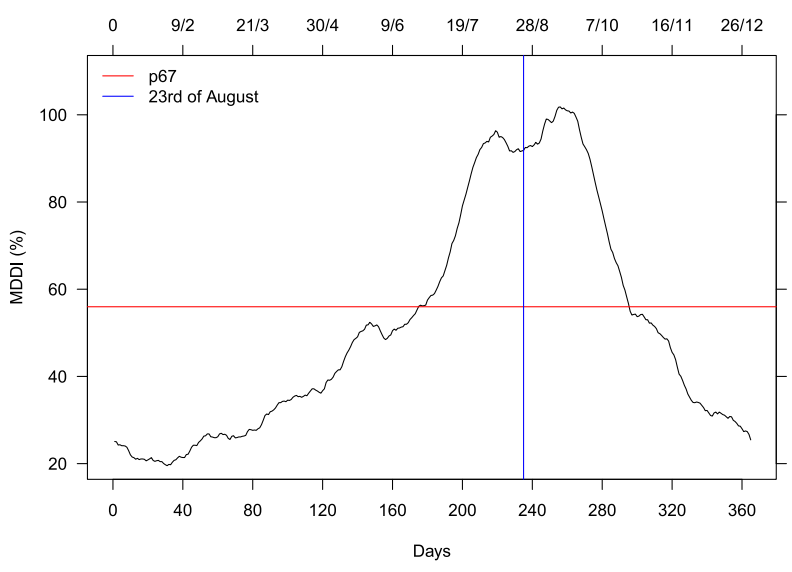

FIG. 3. Daily climatology of the MDDI for the 1949-2014 period. The red line denotes the 67th percentile of the series (p67) and the blue line refers to the central day of those in which the climatological index exceeds p67. The dates corresponding to the day of year are indicated in the upper $x$ axis.

winter (December-January) the index values are low, ranging between $20 \%$ and $30 \%$. After the climatological minimum at the beginning of February, the index starts a slow increase, which speeds up from day 120 on and lasts up to around day 200 , when values close to $100 \%$ are reached. These high values, characteristic of a welldeveloped monsoonal circulation, prevail up to day 270 , when the averaged index starts a rapid decrease until December.

\section{2) CHARACTERIZATION OF THE MONSOON SEASON}

As stated in section 1, the WNPSM onset (withdrawal) progresses eastward (westward) within its domain. This displacement is similar for other monsoons. For instance, precipitations associated with the ISM start in Kerala (southern India), and advance northward. Notwithstanding that rains might reach northern India a month later, the ISM onset is considered a unique event and by definition it is assigned to the beginning of the rainy season in Kerala (Ordoñez et al. 2016). On the contrary, the WNPSM onset is usually determined locally. Thus, the onset date at a given location coincides with the early monsoon precipitation in that particular location (Zhang 2010; Zeng and Lu 2004). In this paper, an approach similar to the ISM case was considered. In this sense, we established a unique WNPSM onset date based on a well-developed monsoon circulation over the western North Pacific.

The 67th percentile (p67) of the MDDI averaged series for the period 1949-2014 (red line in Fig. 3) was chosen as an objective threshold to define the monsoon season for any particular year. This threshold implies an average duration of the monsoon length of 4 months,
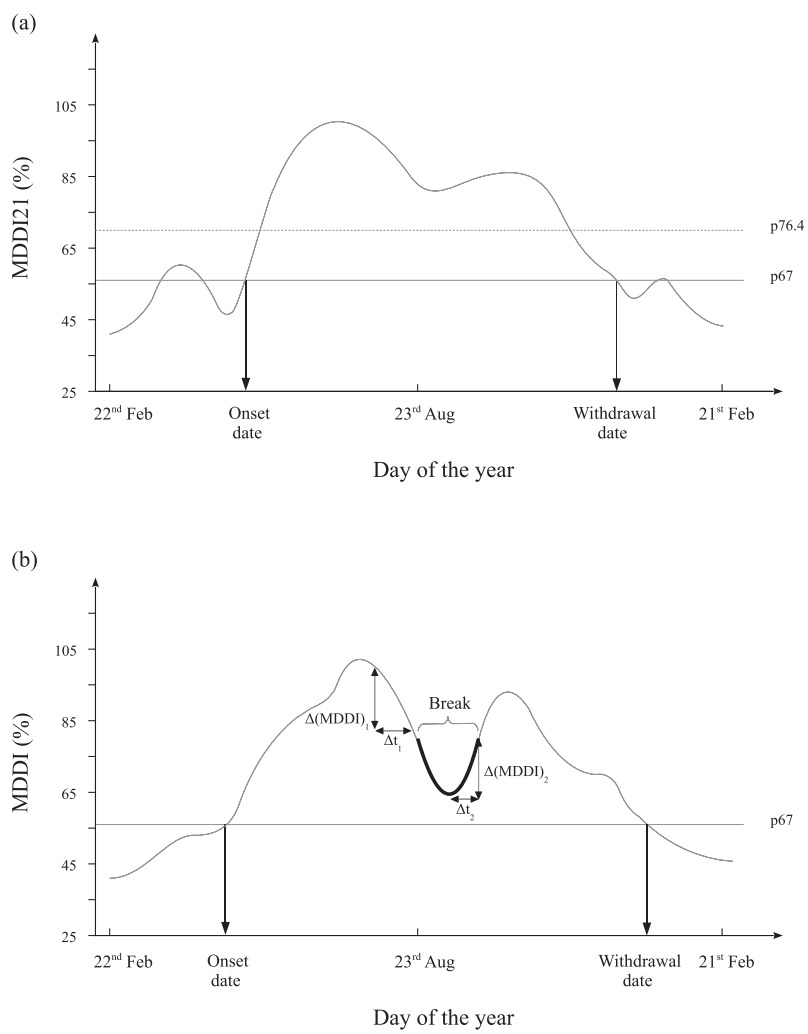

FIG. 4. Schemes to determine the (a) onset and withdrawal dates and (b) monsoon breaks for a given year. In (a) the solid curve represents the running mean of the MDDI series considering a window of 21 days (MDDI21), whereas in (b) it refers to the MDDI. The monsoon season corresponds to those days in which MDDI21 exceeds the p67 threshold (the 67th percentile of the climatological MDDI). A second threshold is set (p76.4, 30\% greater than p67) in order to assure that the p67 threshold is being crossed leading to (coming from) a well-developed monsoon for the onset (withdrawal), avoiding bogus assignments. In (b) $\Delta$ MDDI indicates the MDDI difference between 2 days $(\Delta t)$.

which is coherent with previous studies (Yasunari 1979; Wang and LinHo 2002; Goswami and Xavier 2005). Unlike the smooth progression of the averaged MDDI, the evolution of the MDDI displays strong interannual and intraseasonal variability. In this regard, due to its definition as a percentage of days with wind blowing from a prevalent direction over a relatively small sample of days, the raw MDDI shows an evolution in "discrete steps." To better locate the rapid increase (decrease) in the MDDI characteristic of the WNPSM onset (withdrawal), we first smoothed the raw MDDI by computing the 21-day moving average (MDDI21 hereafter). The onset (withdrawal) of the WNPSM corresponds to the first (last) day in which the MDDI21 exceeded the p67 threshold. Nevertheless, in a number of years the MDDI21 crosses the p67 threshold more than twice (see an idealized example in Fig. 4a). For these cases, we required a second 
criterion in order to assure that the p67 threshold is being crossed leading to (coming from) a well-developed monsoon for the onset (withdrawal), avoiding bogus assignments caused by minor fluctuations of the index associated with transient eddies. Thus, the onset was assigned to the first day in which the MDDI21 exceeded the p67 threshold provided that the index kept increasing up to the 76.4th percentile of the MDDI, p76.4 (a value 30\% higher than p67). Equally, the withdrawal was assigned to the last day in which the MDDI21 exceeded the p67 threshold after a continuous decrease from the same p76.4 value.

Between the onset and withdrawal dates, the MDDI can display sudden decreases related to monsoon breaks. To identify those events, we considered the parameters $\Delta$ MDDI $=38$ units and $1 \leq \Delta t \leq 24$ days and proceed through the following steps:

1) For each day $d$ between the onset and withdrawal dates, MDDI differences between days $d$ and $d+\Delta t$ were computed.

2) When any of those values exceeded $\Delta$ MDDI units $\left(\Delta \mathrm{MDDI}_{1}\right.$ in Fig. $4 \mathrm{~b}$ ), we identified the subsequent relative minimum of the MDDI.

3) A break was defined when the index increased $\Delta$ MDDI units within the $\Delta t$ days following the date of the minimum ( $\Delta \mathrm{MDDI}_{2}$ and $\Delta t_{2}$ in Fig. $\left.4 \mathrm{~b}\right)$. The beginning (end) of the break corresponds to the first day before (after) the minimum that meets the MDDI difference of $\triangle$ MDDI units from the minimum MDDI value (thick line in Fig. 4b).

It is worth mentioning that the $\Delta \mathrm{MDDI}$ and $\Delta t$ values are associated with the MDDI fluctuation rhythm. The values $35 \leq \Delta$ MDDI $\leq 50$ units and $21 \leq \Delta t_{\max } \leq$ 50 days were first considered, obtaining mostly the same breaks. Nevertheless, $\Delta$ MDDI $=38$ units and $\Delta t_{\text {max }}=24$ days were chosen as they represent great changes of the directional index without being too restrictive. On the other hand, although $\Delta t_{\max }$ days after the MDDI minimum is fixed, there is not a $\Delta t_{\max }$ requisite before the minimum. The longest break event had a duration of 46 days, whereas the shortest break endured 11 days. Therefore, the duration of the break is not fixed, different from other studies (e.g., $\mathrm{Xu}$ and $\mathrm{Lu}$ 2015).

\section{Results}

The annual evolution of the MDDI reflects a high interannual variability. As an example of different onset and withdrawal dates, lengths of the monsoon season, and number of breaks, Figs. 5a-d show the MDDI evolution for the years 1954, 1961, 1987, and 2000, respectively. The year 1954 was characterized by a short
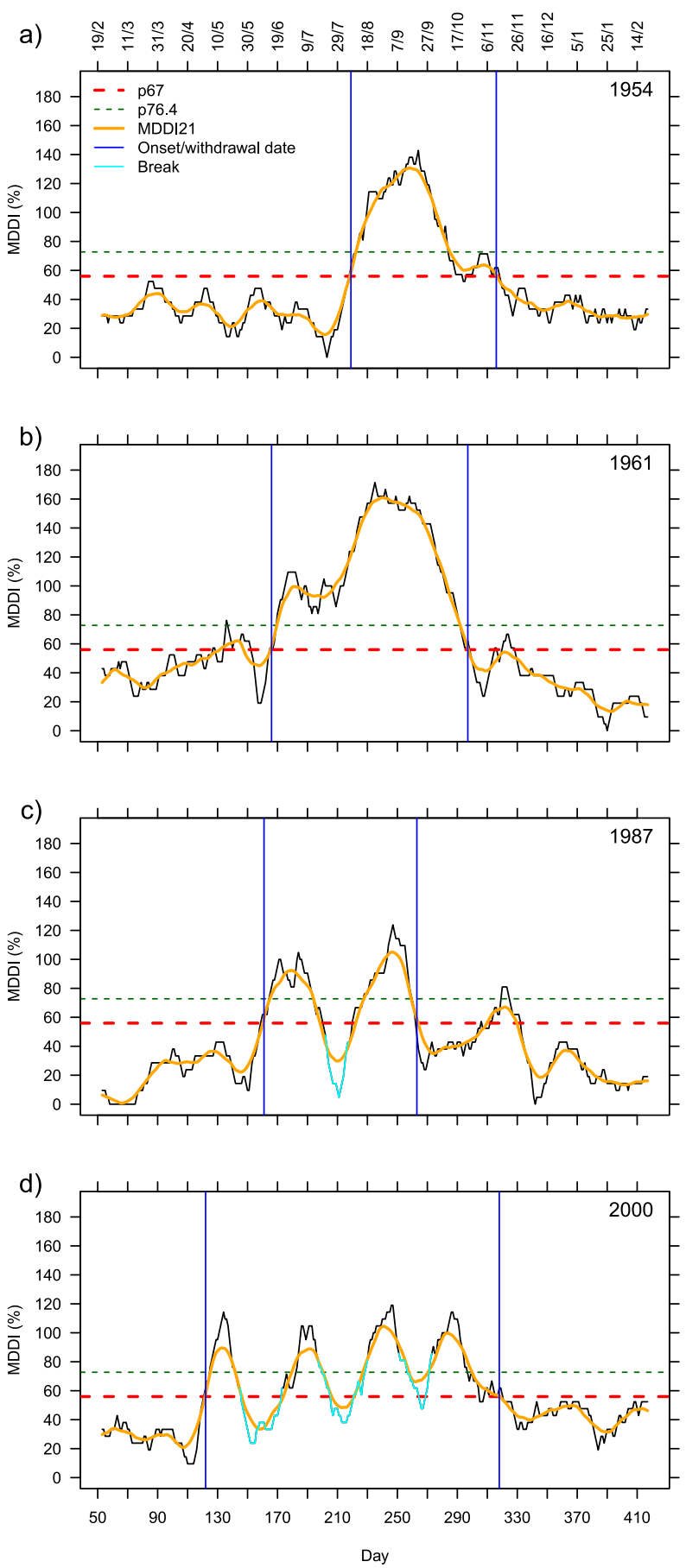

FIG. 5. Daily evolution of the directional index for (a) 1954, (b) 1961, (c) 1987, and (d) 2000. The thick yellow line refers to the 21-day sliding mean of the index. Breaks are bold with sky-blue lines. Horizontal dashed lines mark the thresholds to define the monsoon season (see section 2 for details). Vertical solid lines refers to the onset and withdrawal of the WNPSM. The dates corresponding to the day of the year are indicated on the upper axis of (a). 
a)

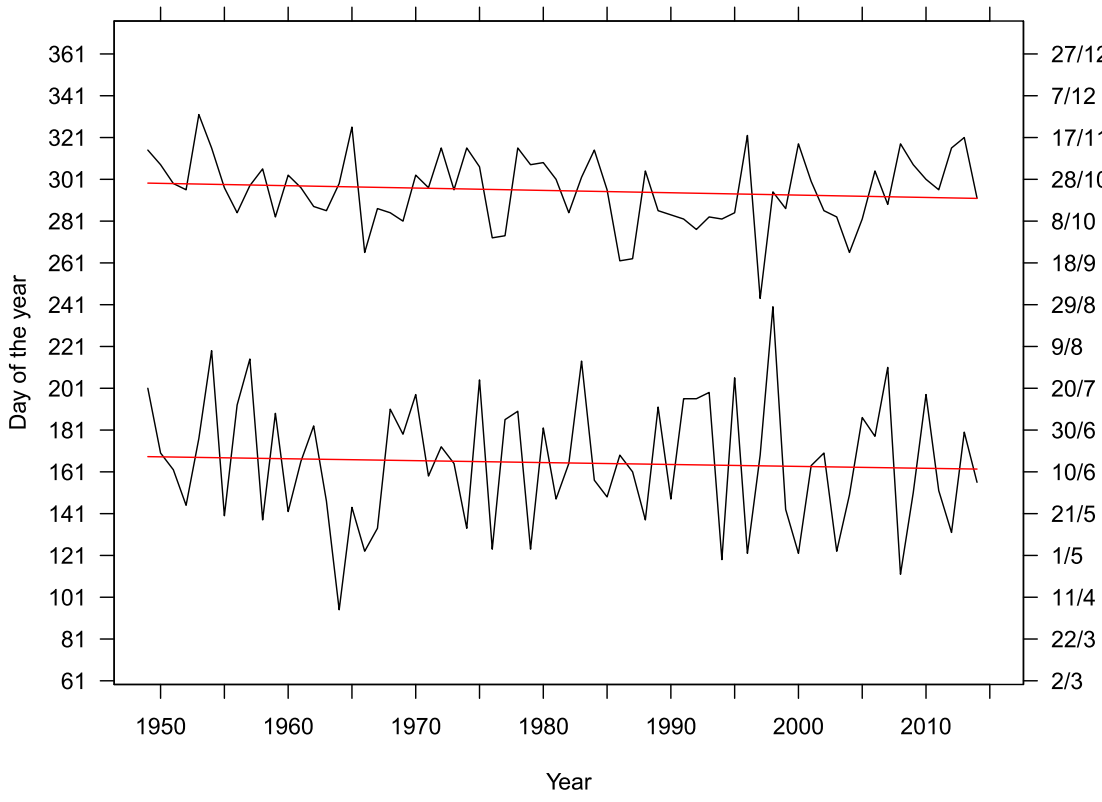

b)

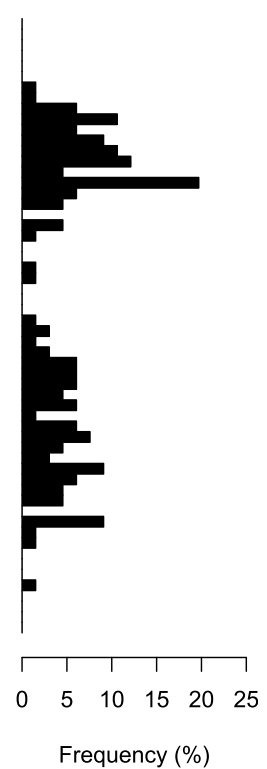

FIG. 6. (a) Annual evolution of the onset and withdrawal dates of the WNPSM and (b) its relative frequency considering added values at 5-day intervals for the period 1949-2014.

monsoon that was fully developed by late July (day 219 of the year) and lasted until early November (day 316). During that year, the monsoon did not experience any break. The absence of breaks was also the case in 1961 (Fig. 5b) but in this example, the monsoon started earlier (mid-June) and was well developed until late October. Figure 5c shows a typical case of a monsoon characterized by a single break, which was evidenced by a strong and sustained decline in the MDDI by the end of July. In this year (1987), both the onset and withdrawal dates were quite early (mid-June and mid-September, respectively). Finally, Fig. 5d shows a multibreak example for the year 2000 . In this case, after a premature onset (early May), the MDDI shows three minima that fulfilled our criteria to be classified as monsoon breaks (centered on days 159,213 , and 262), followed by a late withdrawal in mid-November.

\section{a. Evolution of the monsoon season}

The annual evolution of the WNPSM onset and withdrawal dates during the 1949-2014 period is shown in Fig. 6a. We did not find statistically significant trends, but there is an evident interannual variation, especially for the onset series. In this sense, in about a third of the analyzed years, there is a difference of roughly two months between the onset date of consecutive years. In addition, the range of the onset date is wider than the range of the withdrawal. The monsoon can start between early May and early August whereas it tends to end between October and November. The most frequent withdrawal date occurred between 13 and 17 October whereas there was not a clear preferential date for the monsoon to start (Fig. 6b). Regarding the length of the monsoon season (number of days between the onset and the withdrawal dates), the most frequent case corresponds to a duration of 130 to 150 days $(24.11 \%)$, followed by 90 110 days $(19.71 \%), 150-170$ days $(18.21 \%), 70-90$ days $(13.53 \%)$, and $110-130$ days $(10.59 \%)$. The remaining intervals are below $7 \%$.

The date and length of the breaks are also rather variable from year to year. Figure $7 \mathrm{a}$, represents the days classified as breaks within the monsoon (in successive "inactive days") during the 1949-2014 period. According to the MDDI, the most frequent case corresponds to monsoon seasons with a single break $(38.42 \%)$, although 3 or 4 breaks per season were detected as well $(10 \%)$. It is interesting to note that monsoons without any breaks is the second most frequent case $(28.95 \%)$. WNPSM breaks were detected between June and late September; however, they tend to occur from mid-August to early September and from late June to mid-July (Fig. 7b). The duration of a break varies between 11 and 46 days although around $55 \%$ lasted between 20 and 30 days. In addition, we found that the number of inactive days is significantly related to the duration of the monsoon season; that is, 
a)

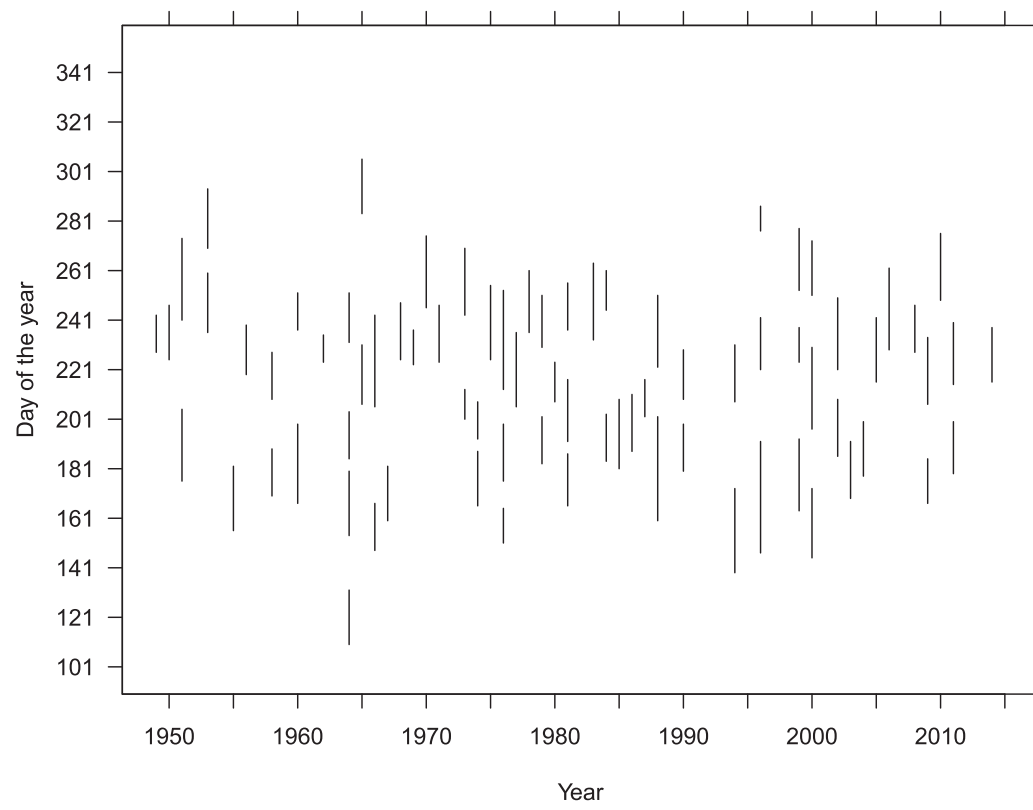

b)

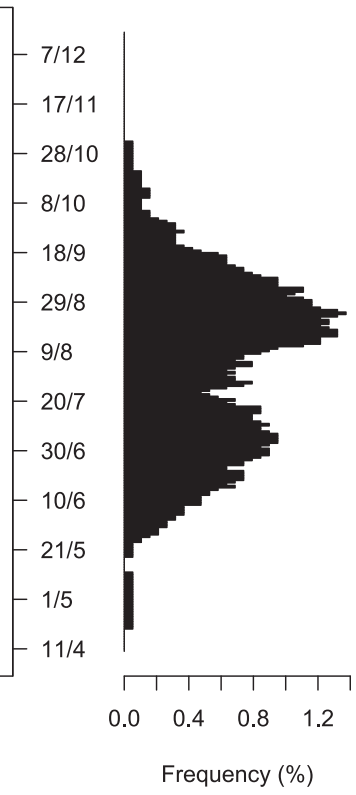

FIG. 7. (a) WNPSM break days and (b) their relative frequency for the period 1949-2014.

the longer the monsoon, the greater the number of inactive days ( $p<0.01$; figure not shown).

To assess the changes in precipitation associated with the beginning (end) of the monsoon season, Fig. 8a (Fig. 8b) shows the difference of composited daily precipitation anomalies from the 5 th to 10 th days subsequent and previous to the onset (withdrawal) date. This analysis is limited to the 1951-2007 period due to the availability of the precipitation dataset. After the WNPSM onset, precipitation increases in the Mariana Islands, southeast Indochina, and the northern Philippines. The westernmost area of the Philippines registers differences of $12 \mathrm{~mm}_{\text {day }}{ }^{-1}$ (Fig. 8a). In contrast, precipitation decreases in Malaysia, Sumatra, and Borneo, which agrees with the northward displacement of the ITCZ during boreal summer. In relation to the withdrawal date, the greatest changes in precipitation $\left(-6 \mathrm{~mm} \mathrm{day}^{-1}\right)$ are observed in the northern Philippines (Fig. 8b). Furthermore, a reduction in precipitation is also detected in the confluence among Vietnam, Cambodia, and Laos. On the contrary, precipitation in Malaysia increases up to $4 \mathrm{~mm} \mathrm{day}^{-1}$. According to these results, the WNPSM mainly affects the precipitation in the rectangular area in Fig. 8a. This region is similar to the WNPSM domain established by Wang and LinHo (2002), with the only exception of western Indochina, which was considered as a transitional zone. It is worth mentioning that in this analysis we also considered the intervals $1-5,1-10$, and $10-15$ days before and after the onset or withdrawal dates. In all cases for both the monsoon beginning and end, precipitation patterns were similar except by the magnitude of the anomalies (the further from the monsoon date, the greater precipitation difference). WNPSM breaks, considered as a weakening of the monsoon, might be also associated with changes in the precipitation over the western North Pacific. Figure 8c shows the difference of daily precipitation anomalies during active and inactive days. In this figure, red (blue) colors refer to regions where precipitation increases during active (inactive) days. The greatest precipitation differences $\left(12 \mathrm{~mm} \mathrm{day}^{-1}\right)$ are located in the northern Philippines and the western coast of India. Precipitation also increases in central India, the coast of Myanmar, and eastern Indochina during active days. In contrast, Indonesia, northeast India, and Bangladesh suffer a decrease in precipitation up to $8 \mathrm{~mm} \mathrm{day}^{-1}$.

Figure 9 shows the vertical velocity anomalies at $500 \mathrm{hPa}$ for the post-satellite 1980-2014 period to assess the impact of the MDDI monsoon dates on the precipitation over the ocean. For the onset and break cases (Figs. 9a,c) the vertical velocity anomalies are of the expected sign, highly significant, and evident over a broad area. For the withdrawal case (Fig. 9b) the increase of the vertical velocity associated with the enhanced subsidence and the consequent decrease in precipitation around the withdrawal are also found, although in this case the anomalies reach statistical 
a) onset $(d+5: d+10)-$ onset $(d-10: d-5)$

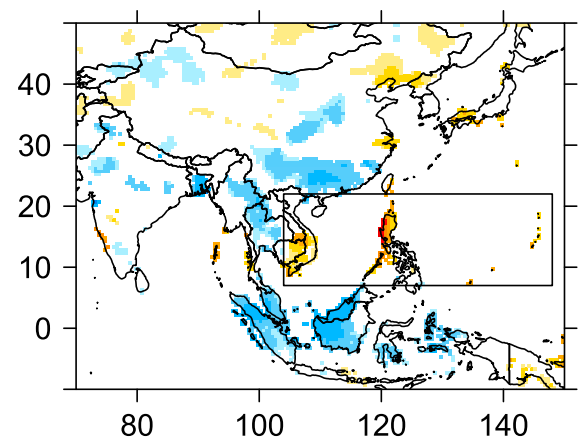

b) end $(d+10: d+5)$ - end $(d-10: d-5)$

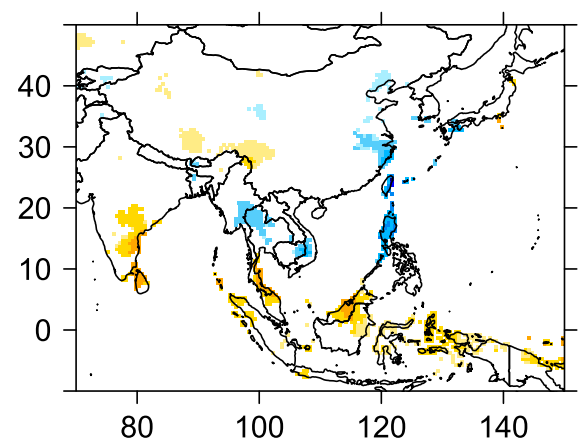

c) Active - inactive monsoon days
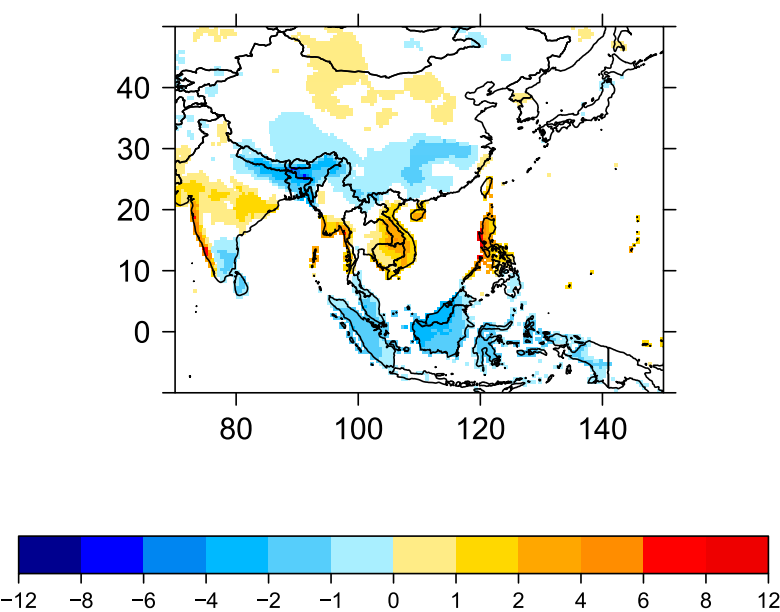

FIG. 8. Composite of the differences in daily precipitation anomalies $\left(\mathrm{mm} \mathrm{day}^{-1}\right)$ between the 5 th and 10 th days before and after the (a) onset and (b) withdrawal dates, and (c) active and inactive monsoon days for the period 1951-2007. Color scale denotes differences that are statistically significant $(p<0.05)$ a) onset $(d+5: d+10)-$ onset $(d-10: d-5)$

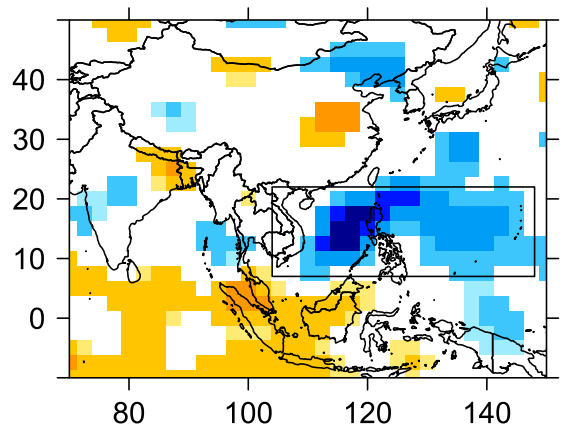

b) end $(d+10: d+5)$ - end $(d-10: d-5)$

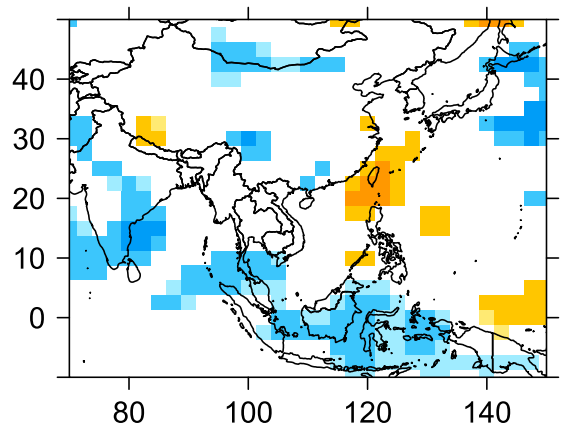

c) Active - inactive monsoon days

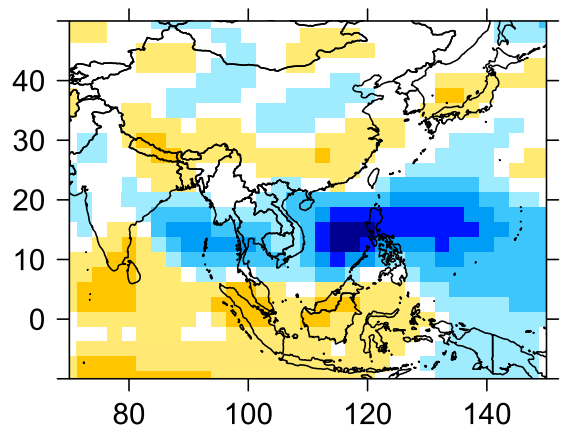

FIG. 9. Composite of the differences in daily vertical velocity at $500 \mathrm{hPa}$ anomalies $\left(\mathrm{Pa} \mathrm{s}^{-1}\right)$ between the 5 th and 10th days before and after the (a) onset and (b) withdrawal dates, and (c) active and inactive monsoon days for the period 1980-2014. Color scale denotes differences that are statistically significant $(p<0.1)$.

significance in a smaller area, restricted to parts of the South China Sea and the Philippine Sea (this area would include most of the WNP region if a slightly lower level of confidence was used). 


\section{b. Variability of monsoon dates}

\section{1) Onset And Withdrawal DATes}

It is widely recognized that one of the factors that most contribute to the interannual changes of the WNPSM onset and withdrawal is the variability of the tropical Pacific SST, in particular the EP ENSO. In this sense, the negative SST anomalies in the WNP associated with an EP El Niño ultimately imply the development of a low-level anomalous anticyclone over the WNP (WNPAC) around October, which persists until the following summer (Wu and Wang 2000; Wang et al. 2000; Wang and Zhang 2002; Li et al. 2017). In these circumstances, the seasonal migration of the monsoon trough, the development of convection and the WNPSM onset are delayed. On the other hand, the development of the WNPAC in fall (Wang and Zhang 2002) leads to a fast weakening of the monsoon trough and, therefore, to an early WNPSM withdrawal. Analogous processes occur with EP La Niña but with opposite anomalies, which implies an earlier onset and late withdrawal during the EP La Niña developing and decaying phases, respectively. Several additional mechanisms have been proposed to explain the formation and maintenance of the WNPAC, including the contributions of the tropical Pacific, the South China Sea, the Indian Ocean, and even the Atlantic Ocean [see Li et al. (2017) for a review].

In this section we test whether the onset and withdrawal dates determined by the MDDI are sensitive to EP ENSO as described in literature. In addition, we have included the CP ENSO in the analysis due to its strong relationship with the WNPSM (Weng et al. 2007, 2011; Lee et al. 2014; Vega et al. 2018). We performed a running correlation analysis between both ENSO indices (EN3 and EMI) and the onset and withdrawal dates as well as the monsoon duration, considering a sliding window of 31 years and different seasonal lags (Fig. 10). In this way, the correlation value assigned to a given year $Y$ corresponds to the Pearson correlation coefficient when considering the period from $Y-15$ to $Y+15$. Seasonal lags from the previous year to the following one to the analyzed monsoon (indicated respectively as "season - 1" and "season + 1" in Fig. 10) have also been included in the analysis.

Regarding the EP ENSO influence on monsoon dates, high (low) values of SST anomalies from the previous summer (JJA - 1) to spring (MAM) in the EN3 region correspond to late (early) WNPSM onset dates (Fig. 10a). Similarly, Fig. 10b shows that the monsoon tends to finish earlier (later) when the EP SST anomalies are positive (negative) from summer (JJA) to the following spring
$(\mathrm{MAM}+1)$. Furthermore, Fig. 10c suggests that the SST impacts on monsoon duration tend to follow more closely that of the onset. Thus, the monsoon tends to have a shorter (longer) duration under EP El Niño (La Niña) conditions from the previous autumn to summer (SON - 1 to JJA). Nevertheless, Figs. 10a-c reveal that those relationships were weaker before the 1980s.

On the other hand, CP ENSO does not seem to modulate the WNPSM onset significantly (Fig. 10d). In contrast, positive (negative) SST anomalies in central Pacific from spring (MAM) to autumn (SON) are related to an earlier (later) monsoon withdrawal (Fig. 10e), especially in the 1970s. This relationship is weaker but more stable along the study period than that corresponding to EP ENSO. In relation to the monsoon season length, longer (shorter) monsoons are associated with negative (positive) EMI values from the summer to the spring preceding the monsoon (JJA-1 and MAM, respectively) from the 1980s on (Fig. 10f). The influence of the central Pacific SST on WNPSM dates is ultimately due to the anomalous atmospheric circulation over the WNP. CP El Niño is associated with an anomalous cyclone over the WNP, which tends to disappear in winter and a WNPAC emerges instead (Zhang et al. 2011). In consequence, the WNPSM is likely to finish earlier. In addition, the WNPAC becomes weaker or even disappears in the following spring (Feng et al. 2011), which suggest that the WNPSM onset might not be affected by a previous CP ENSO.

\section{2) MONSOON BREAK DATES}

A comparison between break dates obtained using the MDDI and previous studies was carried out. First, we performed a kernel density estimation (KDE) with the Gaussian kernel function (Gramacki 2018) considering the 1975-94 period, corresponding to that of Wang and $\mathrm{Wu}$ (1997). The KDE relative maxima coincide with the dry phases of these authors, except by cycle IV related to the monsoon withdrawal (see Table 1). Within those dry phases, Wang and Xu (1997) also identified two climatological breaks in northern Philippines (5-9 July and 3-7 September). Therefore, there is a good agreement among those studies and ours for the common period. However, when considering the 1949-2014 period, peaks of the KDE are displaced, especially from mid- to late August, overlapping the wet phase of cycle III. In this sense, $\mathrm{Xu}$ and $\mathrm{Lu}$ (2018) revealed a decadal change of the WNPSM break date in 2002-03. Therefore, we assessed the decadal variability of our breaks dates by performing a decadal KDE throughout the 1950-2014 period (Fig. 11). In general, the break distribution is bimodal; that is, inactive days are more likely to occur 


\section{a) EN3 - Onset}

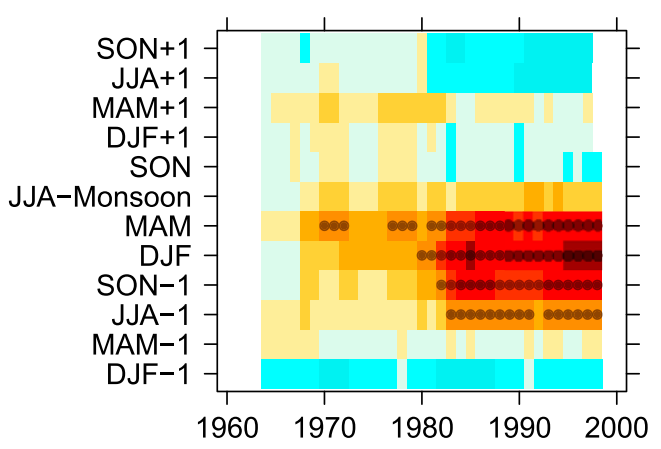

\section{b) EN3 - Withdrawal}

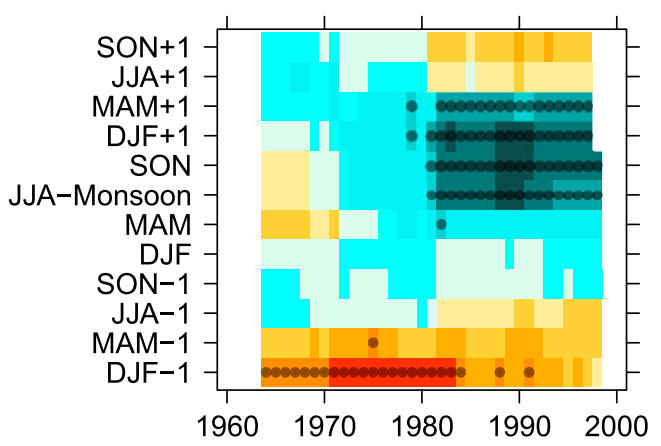

\section{c) EN3 - Duration}

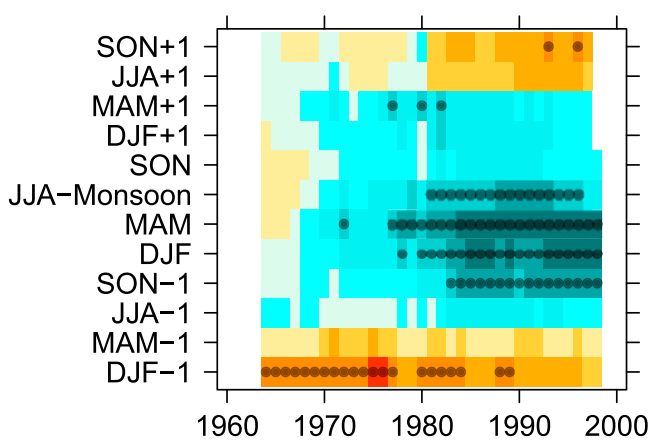

d) EMI - Onset

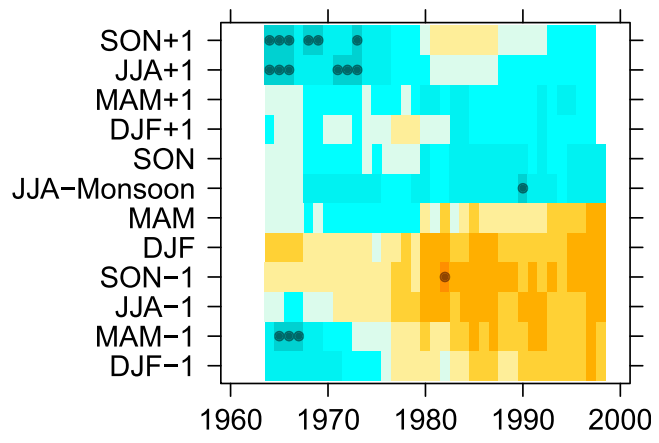

\section{e) EMI - Withdrawal}

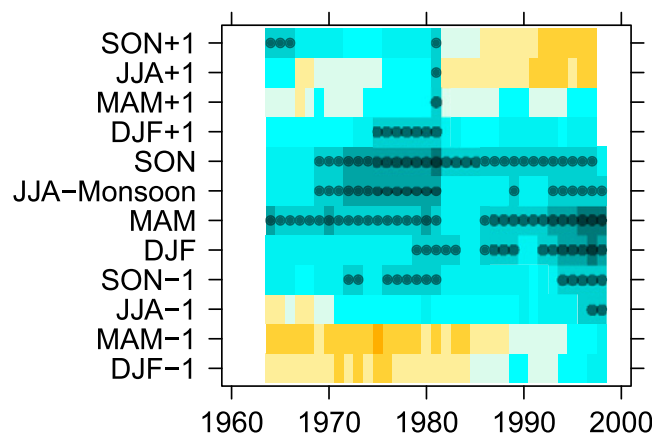

\section{f) EMI - Duration}

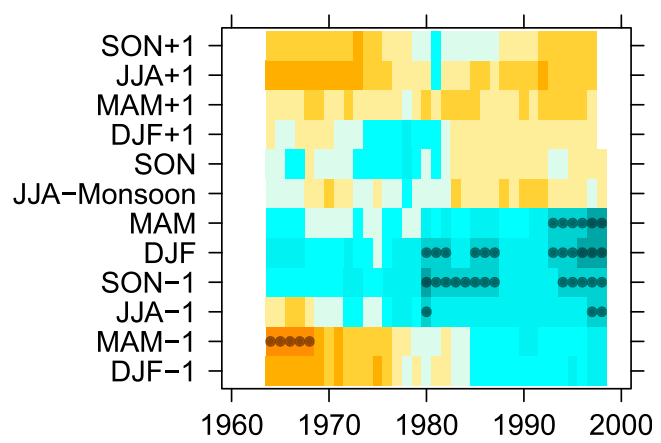

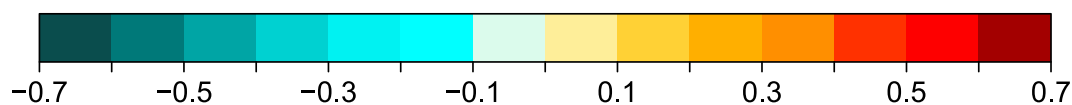

FIG. 10. Lag sliding correlation (31-yr window) between the WNPSM (top) onset, (middle) withdrawal, and (bottom) duration and seasonal (a)-(c) EN3 and (d)-(f) EMI. Years correspond to the central year of the sliding $31-y r$ window. Black points indicate statistically significant correlation values $(p<0.1)$.

in two short periods. The second mode, the dominant one in the first three decades, is centered on 25 August. On the contrary, the first mode experiences a decadal variability. In particular, its maximum, on 29 June in the 1950s, advances to 20 June in the 1960s whereas it is delayed until 15 July in the 1970s. On the other hand, the 1980-99 period entails a change in the break KDE, with the first mode being dominant. The decade 


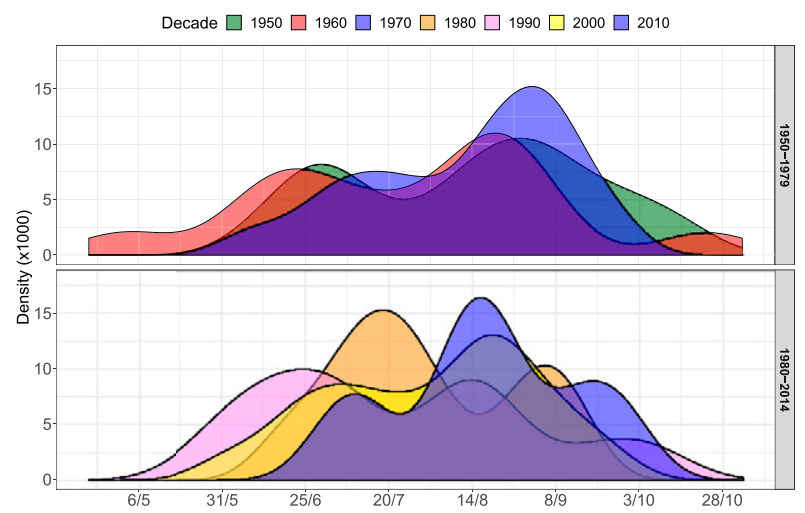

FIG. 11. Kernel density estimation for inactive monsoon days per decade. Inactive monsoon days refer to dates on the $x$ axis.

1980-89 is especially interesting as both modes are delayed (late July and early September, respectively). Afterward, break spells occurred earlier. From 2000 on, the dominant mode switches again.

It was shown that prevailing EP SST conditions in the seasons immediately before and after a monsoon season modulate the onset and withdrawal dates. Thus, it seems plausible that those SST conditions could affect the number of active and inactive days within the monsoon seasons. In this regard, we found that a high number of inactive days corresponded to long-lasting monsoons, usually with EP La Niña or neutral conditions during the previous winter. On the other hand, no breaks were detected in those cases when the previous winter was characterized by a very intense EP El Niño. Another interesting result is that monsoons followed by a winter with EP El Niño conditions show a significantly lower number of inactive days than those with EP La Niña conditions. Results are very similar when the number of breaks per season are analyzed instead the number of inactive days. For CP ENSO we did not find conclusive results.

\section{c. Influence of the WNPSM on tropical cyclones}

As stated in section 1, TC tracks in the western North Pacific are highly modulated by the WNPSM dynamics and vice versa, especially by the occurrence of monsoon breaks (Wang and Wu 1997; $\mathrm{Xu}$ and $\mathrm{Lu}$ 2016). It is therefore interesting to analyze the differences in the wind circulation during active and inactive days, determined by the MDDI, and their implications for TC tracks. Figures $12 \mathrm{a}$ and $12 \mathrm{~b}$ show the composite of daily SLP and surface wind anomalies for active and inactive days, respectively, throughout the 1949-2013 period. During active (inactive) monsoon days, an anomalous cyclonic (anticyclonic) circulation and negative (positive) SLP anomalies are observed over the area $10^{\circ}-28^{\circ} \mathrm{N}$, $110^{\circ}-140^{\circ} \mathrm{E}$. These circulation changes are concurrent with differences in the distribution of TC over the WNP. The number of TCs per active and inactive day (in \%) in each $5^{\circ} \times 5^{\circ}$ square throughout the 1949-2013 period is shown in Figs. 12c and 12d, respectively. During active days a significant increase of TC occurrence is found within $15^{\circ}-20^{\circ} \mathrm{N}, 110^{\circ}-130^{\circ} \mathrm{E}$ (Fig. $12 \mathrm{c}$ ) as compared to inactive days (Fig. 12d). In addition, the maximum number of TCs per square in active days $(8 \%)$ is greater than during monsoon breaks (5\%). To easily compare the distribution of TCs per active and inactive days we also computed their differences (Fig. 12e). The greatest increase in the number of TCs occurs in the South China Sea and the Philippines Sea, reaching a maximum difference of about $5 \%$ by the coast of central Vietnam. On the other hand, statistically significant negative differences are found to the south of the Korean peninsula and to the north of the Mariana Islands $\left(20^{\circ}-35^{\circ} \mathrm{N}, 145^{\circ}\right.$ $\left.150^{\circ} \mathrm{E}\right)$. In this sense, Fig. $12 \mathrm{e}$ suggests that TCs tend to follow a zonally oriented track from the western Pacific into the South China Sea during active days whereas TC trajectories tend to recurve northward, from the western Pacific toward the Korean peninsula and Japan, during WNPSM breaks.

In the previous analysis we considered both types of monsoon days (active and inactive) independently of their dates. Nevertheless, the seasonal evolution of SSTs could impact the number of TCs as well as on their genesis region (Zhan et al. 2012; Chia and Ropelewski 2002; Chen et al. 2004). Therefore, a similar analysis to the one presented in Figs. 12c-e was carried out but at monthly scale (considering months with high WNPSM breaks frequency, June-September; Fig. 13). During active days, the frequent passage of TCs from the Philippines Sea to the South China Sea is common for all months (Fig. 13, left column). Differences among them are related to the region size and the location of TC maxima. For instance, that maximum is found in the Philippines Sea in July and August whereas it is located in the South China Sea in June and September. Furthermore, the largest region with more than $7 \%$ of TCs per day and square, covering from northern Philippines to southern Japan, is found in August. Regarding the inactive days (Fig. 13, center column), the TC monthly distributions show greater changes than during active days. For example, only in August and September are squares found with more than $5 \%$ of TC per day but in different regions depending on the month. The right column in Fig. 13 shows the differences between active and inactive days in the number of TCs for each month. It is interesting to notice that negative differences to the north of the Mariana Islands are only observed in July and August, suggesting more meridional TC tracks during monsoon 
a) Active days

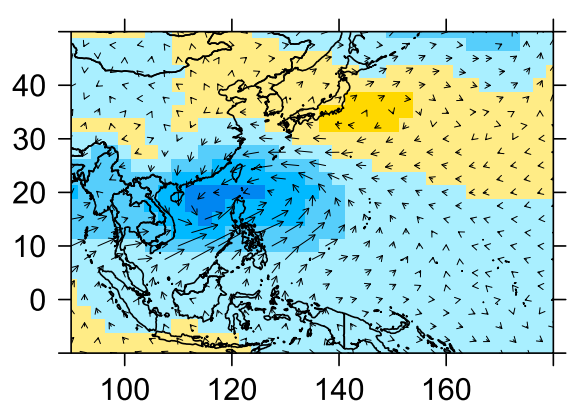

b) Inactive days

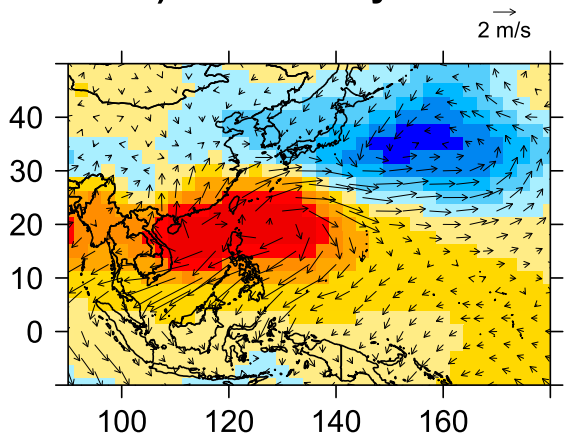

$\mathrm{Pa}$

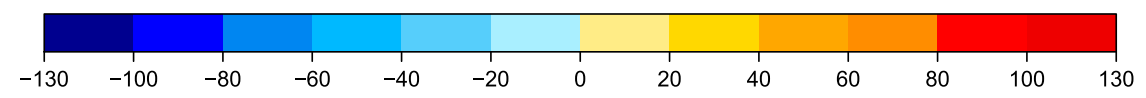

c) TC/Active days

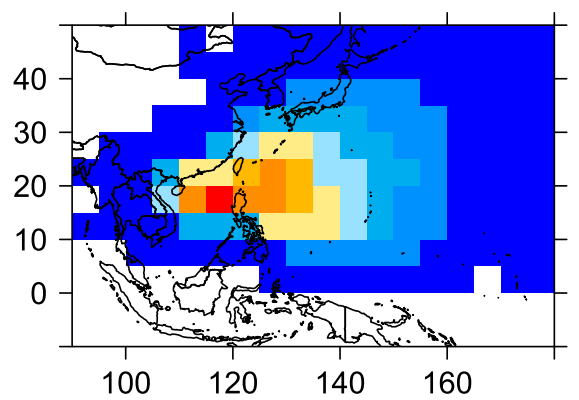

d) TC/Inactive days

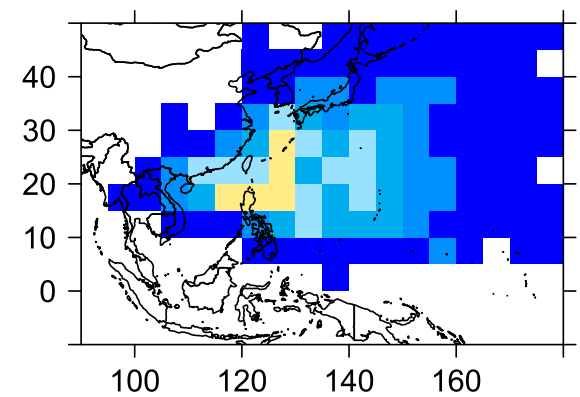

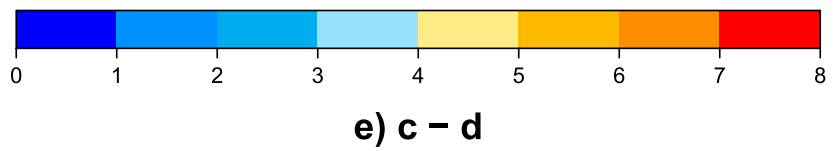
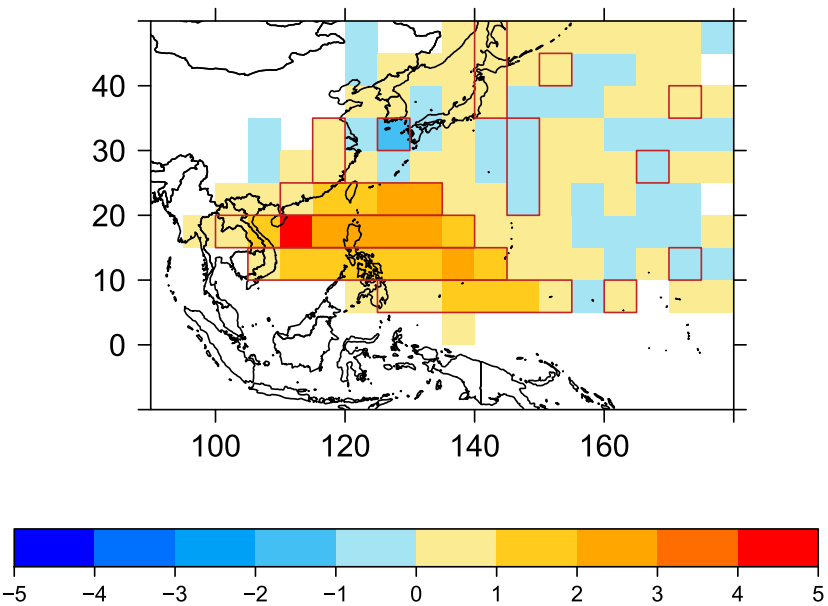

FIG. 12. Composites of SLP (Pa; colors) and wind at $\sigma=0.995\left(\mathrm{~m} \mathrm{~s}^{-1}\right.$; vectors) daily anomalies for (a) active and (b) inactive monsoon days. Spatial distribution of TC $(\%), 5^{\circ} \times 5^{\circ}$ gridded, for (c) active and (d) inactive monsoon days and (e) their differences. All composites were computed considering the period 1949-2013. Contoured cells in (e) indicate statistically significant differences $(p<0.05)$. 
a) TC/act.days Jun

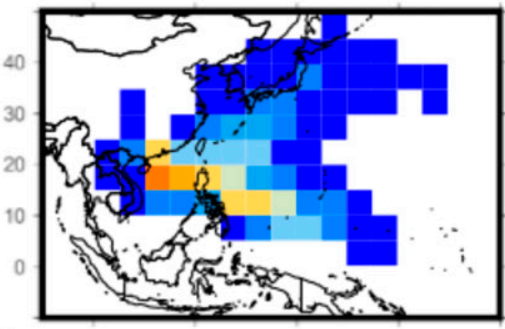

d) TC/act.days Jul

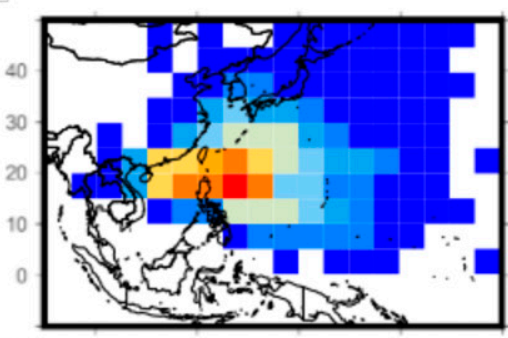

g) TC/act.days Aug

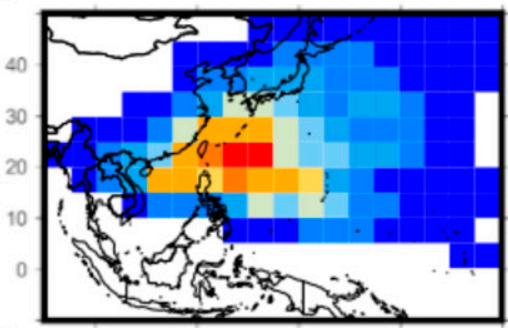

j) TC/act.days Sep

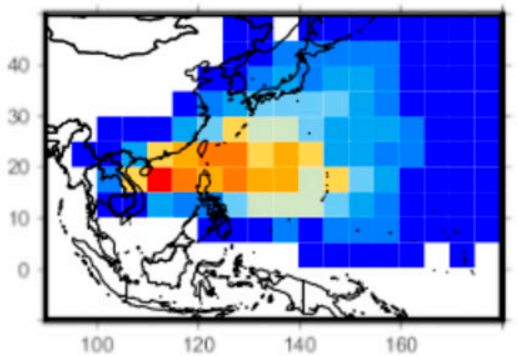

b) TC/inact.days Jun

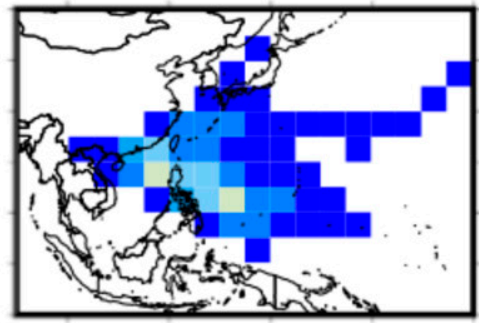

e) TC/inact.days Jul

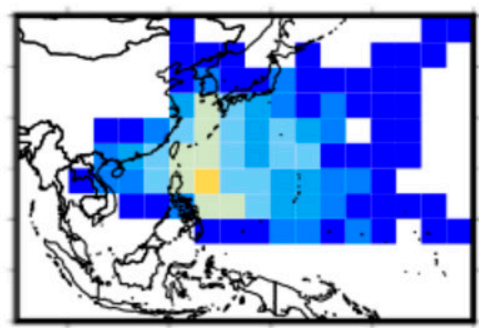

h) TC/inact.days Aug

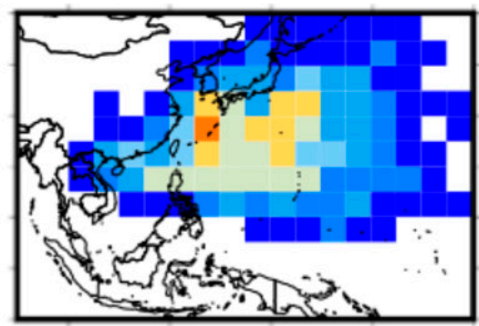

k) TC/inact.days Sep

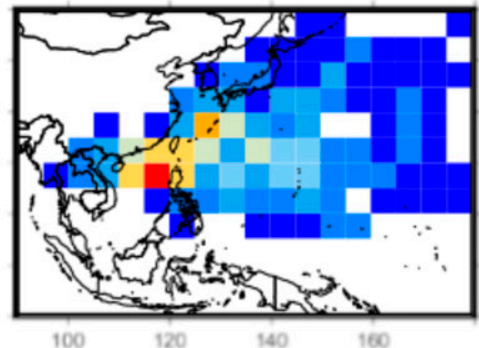

c) $a-b$

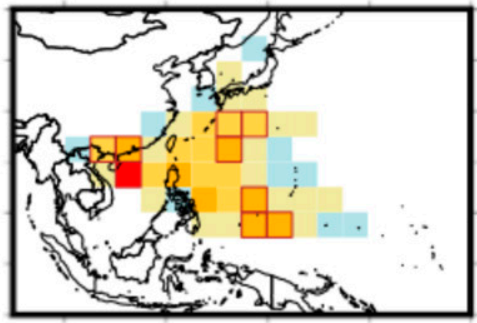

f) d-e

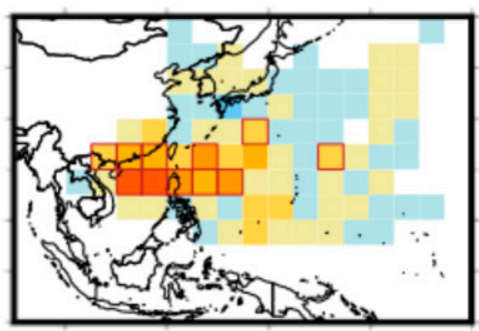

i) $\mathbf{g}-\mathrm{h}$

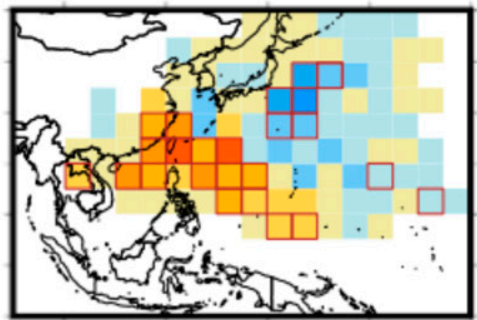

I) $\mathbf{j}-\mathbf{k}$
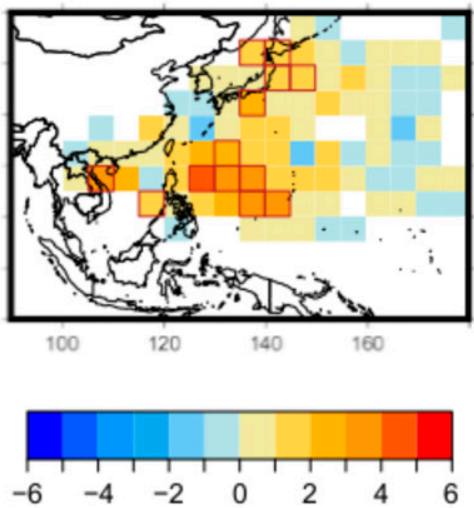

FIG. 13. Spatial distribution $\left(\% ; 5^{\circ} \times 5^{\circ}\right.$ gridded) of TCs during (left) active and (center) inactive periods, and (right) their difference for (a)-(c) June, (d)-(f) July, (g)-(i) August, and (j)-(l) September throughout the 1949-2013 period. Contoured cells in (c), (f), (i), and (l) indicate statistically significant differences $(p<0.05)$. 
breaks (Figs. 13f,i). In particular, the changes in TC track during active and inactive days are clearer for August. For this month, TCs move from the south of the Mariana Islands to eastern China during active days, whereas TC trajectories are north-oriented, reaching the east of Japan, during inactive days (Fig. 13i).

\section{Discussion and conclusions}

A new methodology is presented in order to determine, at regional scale, the beginning and the end of the WNPSM as well as its inactive periods. As a measure of the monsoon development, we used a new index, the MDDI, based exclusively on in situ wind direction observations taken from the raw version of the ICOADS database. The MDDI constitutes an important improvement over previous indices as it allows for exploring the WNPSM variability at a higher temporal resolution along the 1949-2014 period. In this regard, one of the advantages of our approach is the likely extension of the MDDI series back in time as new wind direction observations are incorporated to the ICOADS database (García-Herrera et al. 2018). This is particularly relevant as daily precipitation observations over the ocean, the series usually used for defining long-term monsoonal indices, are not available for a comparable period.

Several reanalyses are available for the twentieth century (20CR and ERA20C; Compo et al. 2011; Poli et al. 2016, respectively). However, it is not advisable to use them to compute long series of directional indices, especially before the mid-twentieth century (Vega et al. 2018). In this sense, recent research indicate that ICOADS wind speeds, which are assimilated in these reanalyses, are most probably biased toward increasing values, resulting in unrealistic trends for the wind speed (Wohland et al. 2019; Barton et al. 2013). In consequence, changes in sensitive variables, such as the monsoon onset date, could be highly influenced by this nonclimatic signal. Notwithstanding, when we compared the MDDI with similar indices computed with the 20CR and ERA20C data, the three indices showed a remarkable agreement in the 1979-2014 period with significant correlation coefficients around +0.9 $(p<0.05)$. In contrast, the indices computed with both reanalyses show notable discrepancies during the early twentieth century, suggesting that assimilation models can introduce significant uncertainty on wind-based circulation indices. In this sense, the MDDI could be useful to calibrate climate models regarding the WNPSM as it is free of the possible biases due to the nonclimatic trends in the wind velocity and the effect of any assimilation model.

As previously said, the three WNPSM new series presenting the dates for the onset, withdrawal, and breaks, covering the 1949-2014 period, are arguably the main contribution of this paper. Even if these series are computed using a 21-day moving window, they capture adequately both low-level wind and precipitation changes associated with monsoon activity over the WNP, with a precision comparable to algorithms based on the analysis of precipitation or ORL at pentad-like resolution.

In accordance with the literature (Lau and Yang 1997; Wang and Wu 1997; Wu and Wang 2000), our onset series shows a large interannual variability, varying between early May and early August. Wu and Wang (2000) and Yan (1997), with a much shorter period of study, described a shorter interval for the onset to occur. In fact, the interannual variability of our onset series is lower in the 1980s, which mostly overlap periods analyzed in those previous studies. The withdrawal series shows lower interannual variability, with the most frequent date in mid-October. This result is in agreement with previous studies (Wang and Xu 1997; Zeng and Lu 2004; Zhang 2010; Kajikawa and Wang 2012). In particular, our series shows the withdrawal delay after the mid-2000s recently reported by Hu et al. (2019) over the South China Sea.

WNPSM breaks have been characterized for more than 60 years. In particular, our analysis shows that the multibreak character of the Indian summer monsoon (Gadgil and Joseph 2003; Rajeevan et al. 2010) is also observable in the WNPSM. We detected up to four breaks in one season although the occurrence of a single break was the most frequent case $(38.42 \%)$, followed by monsoon seasons without any break $(28.65 \%)$. These results are very much in agreement with the few publications directly dealing with WNPSM breaks, even when those publications usually do not describe more than two events per season (Wang and Xu 1997; Wang and Wu 1997; Xu and Lu 2015).

Break events are more likely to happen from midAugust to early September and from late June to midJuly, as in Wang and Xu (1997) and Wang and Wu (1997). This bimodal distribution shows decadal variability in both the dates and the dominance of the peaks. In this regard, the break between late June and mid-July dominated in the 1980s and the 1990s whereas the break occurring from mid-August to early September prevailed in the remaining decades. Furthermore, our results show the delay of the second peak in the 2000s noted by $\mathrm{Xu}$ and $\mathrm{Lu}$ (2018).

Regarding break duration, we found that around the $55 \%$ of the WNPSM breaks lasted between 20 and 30 days, although the minimum and maximum duration corresponded to 11 and 46 days, respectively. These lengths are consistent with those of the ISM break spells found by Joseph and Simon (2005) using a wind-based index. However, it must be pointed out that break 
definitions based on precipitation or OLR tend to produce shorter events, lasting around 5 days, both for the WNPSM (Xu and Lu 2015, 2018; Wang and Xu 1997) and the ISM (Gadgil and Joseph 2003). Finally, a significant relation between the duration of the monsoon and the number of inactive days has been observed.

It is important to note that our approach provides monsoon dates at regional scale instead of local, which is common in literature, and monsoon impacts on different variables (wind, precipitation, SST, or OLR) are not necessarily concurrent (He et al. 2017). In consequence, our monsoon dates might differ from other studies. This is particularly the case of the monsoon break, which $\mathrm{Xu}$ and $\mathrm{Lu}(2015)$ dated in early August based on changes in OLR over the region $10^{\circ}-20^{\circ} \mathrm{N}, 140^{\circ}-160^{\circ} \mathrm{E}$. Our results also show inactive days in those dates, although not very frequently.

Besides the concordance between the monsoon dates determined by the MDDI and daily precipitation data and vertical velocity, we have assessed how well some known relationships described in literature are reproduced, such as the influence of tropical Pacific SST on the monsoon onset and withdrawal (Wu and Wang 2000; Zhang 2010; Luo and Lin 2017) and changes in tropical cyclone (TC) tracks related to monsoon activity (Lander 1996; Li and Zhou 2018). The literature proposes the variability of the WNPAC as a mechanism for the former relationship (Li et al. 2017; He et al. 2015; Zhang et al. 2011; Karori et al. 2013) whereas changes in TC tracks might be due to the ISO impacts (Xu and Lu 2016; Feng et al. 2013; Li and Zhou 2018).

In accordance with the literature, our results show that the WNPSM tends to start earlier (later) and finish later (earlier) under EP La Niña (El Niño) conditions. Furthermore, we found that the EP ENSO impacts on monsoon duration tend to follow more closely that of the onset. Thus, the monsoon tends to have a shorter (longer) duration under EP El Niño (La Niña) conditions from the previous autumn to the concurrent summer. Interestingly, these relationships were weaker before the 1980s. Regarding CP ENSO, our results do not show an impact over the WNPSM onset, in agreement with Wang et al. (2013). Nevertheless, positive (negative) SST anomalies in central Pacific from the spring to the autumn concurrent with the monsoon season are related to an earlier (later) monsoon withdrawal.

On the other hand, the atmospheric circulation over the WNP depends on the monsoon activity. Thus, an anomalous cyclone (anticyclone) is observed during active (inactive) days. These atmospheric circulation changes affect the TC trajectories over the WNP. We found that TC tend to move between the southern Mariana Islands and southeastern China during active days, whereas they tend to recurve toward higher latitudes, such as to the south of the Korean peninsula and Japan and within the region $20^{\circ}-35^{\circ} \mathrm{N}, 145^{\circ}-150^{\circ} \mathrm{E}$, during breaks. This northward TC displacement is particularly striking in August. Some of the aspects previously mentioned were also observed by Wang and $\mathrm{Wu}$ (1997), even when our analyses are not directly comparable as their wet/dry phases within the 1975-94 period partially overlap with the breaks determined by the MDDI. In relation to the study of $\mathrm{Xu}$ and $\mathrm{Lu}$ (2016), they found the greatest changes in TC to the east of $140^{\circ} \mathrm{E}$. In particular, TC density increases (decreases) in the $27.5^{\circ}-37.5^{\circ} \mathrm{N}, 140^{\circ}-155^{\circ} \mathrm{E}\left(12.5^{\circ}-25^{\circ} \mathrm{N}, 140^{\circ}-160^{\circ} \mathrm{E}\right)$ region during their breaks in early August. In this regard, we only detected an increase of TC within $20^{\circ}-35^{\circ} \mathrm{N}$, $145^{\circ}-150^{\circ} \mathrm{E}$ during our break dates. This difference might be due to the fact that our most frequent break dates are distinct from those of $\mathrm{Xu}$ and $\mathrm{Lu}$ (2016).

As a final remark, we would like to stress the usefulness of the MDDI to study daily features of the WNPSM, a system that affects millions of people and plays an essential role in the global climate. Our new series will hopefully assist the climate modeling community to better capture and understand the complex mechanisms involved in the relationships between the WNPSM and global climate. In particular, the decadal variability of both the WNPSM-ENSO relationship and monsoon breaks need further investigation. In addition, it is estimated that thousands of logbooks remain not digitized in British archives and it is likely that Japanese and Chinese sources could provide data over the D1 and the D2 areas from earlier years (Wheeler and García-Herrera 2008; Grossman and Zaiki 2013). The extension of the MDDI series prior to the mid-twentieth century could be quite relevant to improve our understanding of the WNPSM history and modeling.

Acknowledgments. This research was funded by the Spanish Ministry of Economy and Competitiveness through Project CGL2013-44530-P, Grant BES-2014069733, and by the Junta de Andalucía through group PAIDI-RNM-356. The authors want to acknowledge Nuria Plaza Martín and two anonymous reviewers for their useful commentaries.

\section{REFERENCES}

Ashok, K., S. K. Behera, S. A. Rao, H. Weng, and T. Yamagata, 2007: El Niño Modoki and its possible teleconnection. J. Geophys. Res., 112, C11007, https://doi.org/10.1029/ 2006JC003798.

Barton, E. D., D. B. Field, and C. Roy, 2013: Canary Current upwelling: More or less? Prog. Oceanogr., 116, 167-178, https:// doi.org/10.1016/j.pocean.2013.07.007. 
Cao, X., T. Li, M. Peng, W. Chen, and G. Chen, 2014: Effects of monsoon trough interannual variation on tropical cyclogenesis over the western North Pacific. Geophys. Res. Lett., 41, 4332-4339, https://doi.org/10.1002/2014GL060307.

Chang, C., and G. T. Chen, 1995: Tropical circulations associated with southwest monsoon onset and westerly surges over the South China Sea. Mon. Wea. Rev., 123, 3254-3267, https://doi.org/ 10.1175/1520-0493(1995)123<3254:TCAWSM > 2.0.CO;2.

Chen, T., S. Wang, M. Yen, and W. A. Gallus, 2004: Role of the monsoon gyre in the interannual variation of tropical cyclone formation over the western North Pacific. Wea Forecasting, 19, 776-785, https://doi.org/10.1175/1520-0434(2004) $019<0776$ :ROTMGI $>2.0 . \mathrm{CO} ; 2$.

Chia, H. H., and C. F. Ropelewski, 2002: The interannual variability in the genesis location of tropical cyclones in the northwest Pacific. J. Climate, 15, 2934-2944, https://doi.org/ 10.1175/1520-0442(2002)015<2934:TIVITG >2.0.CO;2.

Choi, K. S., Y. Cha, H. D. Kim, and S. D. Kang, 2016: Possible influence of western North Pacific monsoon on TC activity in mid-latitudes of East Asia. Climate Dyn., 46, 1-13, https:/ doi.org/10.1007/s00382-015-2562-9.

Compo, G. P., and Coauthors, 2011: The Twentieth Century Reanalysis Project. Quart. J. Roy. Meteor. Soc., 137, 1-28, https://doi.org/10.1002/qj.776.

Feng, J., W. Chen, C. Y. Tam, and W. Zhou, 2011: Different impacts of El Niño and El Niño Modoki on China rainfall in the decaying phases. Int. J. Climatol., 31, 2091-2101, https:// doi.org/10.1002/joc.2217.

Feng, X., R. Wu, J. Chen, and Z.-P. Wen, 2013: Factors for interannual variations of September-October rainfall in Hainan, China. J. Climate, 26, 8962-8978, https://doi.org/ 10.1175/JCLI-D-12-00728.1.

Findlater, J., 1969: A major low-level air current near the Indian Ocean during the northern summer. Quart. J. Roy. Meteor Soc., 95, 362-380, https://doi.org/10.1002/qj.49709540409.

Freeman, E., and Coauthors, 2017: ICOADS release 3.0: A major update to the historical marine climate record. Int. J. Climatol. 37, 2211-2232, https://doi.org/10.1002/joc. 4775.

Gadgil, S., and P. V. Joseph, 2003: On the breaks of the Indian monsoon. J. Earth Syst. Sci., 112, 529-558, https://doi.org/ 10.1007/BF02709778.

Gallego, D., P. Ordóñez, P. Ribera, C. Peña-Ortiz, and R. GarcíaHerrera, 2015: An instrumental index of the West African monsoon back to the nineteenth century. Quart. J. Roy. Meteor. Soc., 141, 3166-3176, https://doi.org/10.1002/ qj. 2601

García-Herrera, R., D. Barriopedro, D. Gallego, J. Mellado-Cano, D. Wheeler, and C. Wilkinson, 2018: Understanding weather and climate of the last 300 years from ships' logbooks. Wiley Interdiscip. Rev.: Climate Change, 9, e544, https://doi.org/ $10.1002 /$ wcc. 544

Goswami, B. N., and P. K. Xavier, 2005: ENSO control on the South Asian monsoon through the length of the rainy season. Geophys. Res. Lett., 32, L18717, https://doi.org/10.1029/2005GL023216.

Gramacki, A., 2018: Kernel density estimation. Nonparametric Kernel Density Estimation and Its Computational Aspects, Studies in Big Data series, Vol. 37, Springer, 25-62, https:// doi.org/10.1007/978-3-319-71688-6_3.

Grossman, M. J., and M. Zaiki, 2013: Documenting 19th century typhoon landfalls in Japan. Rev. Asian Pacific Stud., 38, 95-118, http://hdl.handle.net/10928/415.

Guan, B., and J. C. Chan, 2006: Nonstationarity of the intraseasonal oscillations associated with the western North Pacific summer monsoon. J. Climate, 19, 622-629, https://doi.org/ 10.1175/JCLI3661.1.

He, B., Y. Zhang, T. Li, and W. T. Hu, 2017: Interannual variability in the onset of the South China Sea summer monsoon from 1997 to 2014. Atmos. Oceanic Sci. Lett., 10, 73-81, https:// doi.org/10.1080/16742834.2017.1237853.

He, C., T. Zhou, and B. Wu, 2015: The key oceanic regions responsible for the interannual variability of the western North Pacific subtropical high and associated mechanisms. J. Meteor. Res., 29, 562-575, https://doi.org/10.1007/s13351-015-5037-3.

Hirahara, S., M. Ishii, and Y. Fukufa, 2014: Centennial-scale sea surface temperature analysis and its uncertainty. J. Climate, 27, 57-75, https://doi.org/10.1175/JCLI-D-12-00837.1.

$\mathrm{Hu}, \mathrm{P} ., \mathrm{W}$. Chen, and S. Chen, 2019: Interdecadal change in the South China Sea summer monsoon withdrawal around the mid-2000s. Climate Dyn., 52, 6053-6064, https://doi.org/ 10.1007/s00382-018-4494-7.

Janowiak, J. E., and P. Xie, 2003: A global-scale examination of monsoon-related precipitation. J. Climate, 16, 4121-4133, https://doi.org/10.1175/1520-0442(2003)016<4121:AGEOMP> 2.0.CO;2.

Joseph, P., and A. Simon, 2005: Weakening trend of the southwest monsoon current through peninsular India from 1950 to the present. Curr. Sci., 89, 687-694, http://www.jstor.org/stable/ 24111169.

Kajikawa, Y., and B. Wang, 2012: Interdecadal change of the South China Sea summer monsoon onset. J. Climate, 25, 3207-3218, https://doi.org/10.1175/JCLI-D-11-00207.1.

Kalnay, E., and Coauthors, 1996: The NCEP/NCAR 40-Year Reanalysis Project. Bull. Amer. Meteor. Soc., 77, 437-471, https://doi.org/10.1175/1520-0477(1996)077<0437:TNYRP> 2.0.CO;2

Karori, M. A., J. Li, and F. F. Jin, 2013: The asymmetric influence of the two types of El Niño and La Niña on summer rainfall over southeast China. J. Climate, 26, 4567-4582, https://doi.org/ 10.1175/JCLI-D-12-00324.1.

Krishnamurthy, V., and J. Shukla, 2007: Intraseasonal and seasonally persisting patterns of Indian monsoon rainfall. J. Climate, 20, 3-20, https://doi.org/10.1175/JCLI3981.1.

Lander, M. A., 1996: Specific tropical cyclone track types and unusual tropical cyclone motions associated with a reverse-oriented monsoon trough in the western North Pacific. Wea. Forecasting, 11, 170-186, https://doi.org/10.1175/1520-0434(1996)011<0170: STCTTA $>2.0 . \mathrm{CO} ; 2$.

Lansigan, F. P., W. L. de los Santos, and J. O. Coladilla, 2000: Agronomic impacts of climate variability on rice production in the Philippines. Agric. Ecosyst. Environ., 82, 129-137, https:// doi.org/10.1016/S0167-8809(00)00222-X

Lau, K. M., and S. Yang, 1997: Climatology and interannual variability of the Southeast Asian summer monsoon. Adv. Atmos. Sci., 14, 141-162, https://doi.org/10.1007/s00376-997-0016-y.

Lee, E. J., K. J. Ha, and J. G. Jhun, 2014: Interdecadal changes in interannual variability of the global monsoon precipitation and interrelationships among its subcomponents. Climate Dyn., $\mathbf{4 2}$, 2585-2601, https://doi.org/10.1007/s00382-013-1762-4.

Li, R. C. Y., and W. Zhou, 2018: Revisiting the intraseasonal, interannual and interdecadal variability of tropical cyclones in the western North Pacific. Atmos. Oceanic Sci. Lett., 11, 198-208, https://doi.org/10.1080/16742834.2018.1459460.

Li, T., B. Wang, B. Wu, and T. Zhou, 2017: Theories on formation of an anomalous anticyclone in western North Pacific during El Niño: A review. J. Meteor. Res., 31, 987-1006, https:// doi.org/10.1007/s13351-017-7147-6. 
Luo, M., and L. Lin, 2017: Objective determination of the onset and withdrawal of the South China Sea summer monsoon. Atmos. Sci. Lett., 18, 276-282, https://doi.org/10.1002/asl.753.

Mao, J., and J. Chan, 2005: Intraseasonal variability of the South China Sea summer monsoon. J. Climate, 18, 2388-2402, https://doi.org/10.1175/JCLI3395.1.

Murakami, T., and J. Matsumoto, 1994: Summer monsoon over the Asian continent and western North Pacific. J. Meteor. Soc. Japan, 72, 719-745, https://doi.org/10.2151/jmsj1965.72.5_719.

Ordoñez, P., D. Gallego, P. Ribera, C. Peña-Ortiz, and R. GarcíaHerrera, 2016: Tracking the Indian summer monsoon onset back to the preinstrument period. J. Climate, 29, 8115-8127, https://doi.org/10.1175/JCLI-D-15-0788.1.

Pan, C. J., K. K. Reddy, H. C. Lai, and S. S. Yang, 2010: Role of mixed precipitation cloud systems on the typhoon rainfall. Ann. Geophys., 28, 11-16, https://doi.org/10.5194/angeo-28-11-2010.

Poli, P., and Coauthors, 2016: ERA-20C: An atmospheric reanalysis of the twentieth century. J. Climate, 29, 4083-4097, https://doi.org/10.1175/JCLI-D-15-0556.1.

Prasanna, V., 2014: Impact of monsoon rainfall on the total foodgrain yield over India. J. Earth Syst. Sci., 123, 1129-1145, https://doi.org/10.1007/s12040-014-0444-x.

Rajeevan, M., S. Gadgil, and J. Bhate, 2010: Active and breaks spells of the Indian summer monsoon. J. Earth Syst. Sci., 119, 229-247, https://doi.org/10.1007/s12040-010-0019-4.

Ribera, P., R. Garcia-Herrera, and L. Gimeno, 2008: Historical deadly typhoons in the Philippines. Weather, 63, 194-199, https://doi.org/10.1002/wea.275.

Sun, J., J. Ming, M. Zhang, and S. Yu, 2018: Circulation features associated with the record-breaking rainfall over South China in June 2017. J. Climate, 31, 7209-7224, https://doi.org/10.1175/ JCLI-D-17-0903.1.

Tanaka, M., 1997: Interannual and interdecadal variations of the western North Pacific monsoon and Baiu rainfall and their relationship to the ENSO cycles. J. Meteor. Soc. Japan, 75, 1109-1123, https://doi.org/10.2151/jmsj1965.75.6_1109.

Tao, F., M. Yokozawa, Z. Zhang, Y. Hayashi, H. Grassl, and C. Fu, 2004: Variability in climatology and agricultural production in China in association with the East Asian summer monsoon and El Niño Southern Oscillation. Climate Res., 28, 23-30, https://doi.org/10.3354/cr028023.

Tomita, T., T. Yamaura, and Y. Kuwazuru, 2013: Decadal-scale modulation of atmospheric circulation change at the onset of the western North Pacific summer monsoon. SOLA, 9, 161-165, https://doi.org/10.2151/SOLA.2013-036.

Vega, I., D. Gallego, P. Ribera, F. Gómez-Delgado, R. GarcíaHerrera, and C. Peña-Ortiz, 2018: Reconstructing the western North Pacific summer monsoon since the late nineteenth century. J. Climate, 31, 355-368, https://doi.org/10.1175/ JCLI-D-17-0336.1.

Wang, B., 2006: The Asian Monsoon. 3rd ed. Praxis Publishing, $787 \mathrm{pp}$.

—- and L. Wu, 1997: Subseasonal variations of the tropical storm track in the western North Pacific. Mausam, 48, 189-194.

, and X. Xu, 1997: Northern Hemisphere summer monsoon singularities and climatological intraseasonal oscillation. J. Climate, 10, 1071-1085, https://doi.org/10.1175/1520-0442(1997)010<1071: NHSMSA $>2.0 . \mathrm{CO} ; 2$.

— - and LinHo, 2002: Rainy season of the Asian-Pacific summer monsoon. J. Climate, 15, 386-398, https://doi.org/10.1175/ 1520-0442(2002)015<0386:RSOTAP $>2.0$. CO;2.

— , and Q. Zhang, 2002: Pacific-East Asian teleconnection. Part II: How the Philippine Sea anomalous anticyclone is established during El Niño development. J. Climate, 15, 3252-3265, https:// doi.org/10.1175/1520-0442(2002)015<3252:PEATPI >2.0.CO;2.

- , R. G. Wu, and X. H. Fu, 2000: Pacific-East Asian teleconnection: How does ENSO affect East Asian climate? J. Climate, 13, 1517-1536, https://doi.org/10.1175/1520-0442(2000) $013<1517$ :PEATHD $>2.0$. CO 2 .

$\longrightarrow,-$, and K.-M. Lau, 2001: Interannual variability of the Asian summer monsoon: Contrasts between the Indian and the western North Pacific-East Asian monsoons. J. Climate, 14, 4073-4090, https://doi.org/10.1175/1520-0442(2001)014<4073: IVOTAS $>2.0 . \mathrm{CO} ; 2$.

—, LinHo, Y. Zhang, and M.-M. Lu, 2004: Definition of South China Sea monsoon onset and commencement of the East Asia summer monsoon. J. Climate, 17, 699-710, https://doi.org/10.1175/2932.1.

Wang, X., X. Jiang, S. Yang, and Y. Li, 2013: Different impacts of the two types of El Niño on Asian summer monsoon onset. Environ. Res. Lett., 8, 044053, https://doi.org/10.1088/ 1748-9326/8/4/044053.

Weng, H., K. Ashok, S. K. Behera, S. A. Rao, and T. Yamagata, 2007: Impacts of recent El Niño Modoki on dry/wet conditions in the Pacific rim during boreal summer. Climate Dyn., 29, 113-129, https://doi.org/10.1007/s00382-007-0234-0.

_ G. Wu, Y. Liu, S. K. Behera, and T. Yamagata, 2011: Anomalous summer climate in China influenced by the tropical Indo-Pacific Oceans. Climate Dyn., 36, 769-782, https:// doi.org/10.1007/s00382-009-0658-9.

Wheeler, D., and R. García-Herrera, 2008: Ships' logbooks in climatological research. Ann. N. Y. Acad. Sci., 1146, 1-15, https:// doi.org/10.1196/annals.1446.006.

Wohland, J., N.-E. Omrani, D. Witthaut, and N. S. Keenlyside, 2019: Inconsistent wind speed trends in current twentieth century reanalyses. J. Geophys. Res. Atmos., 124, 1931-1940, https://doi.org/10.1029/2018JD030083.

Wu, C.-H., W.-S. Kau, and M.-D. Chou, 2009: Summer monsoon onset in the subtropical western North Pacific. Geophys. Res. Lett., 36, L18810, https://doi.org/10.1029/2009GL040168.

$\mathrm{Wu}, \mathrm{R}$., 2002: Processes for the northeastward advance of the summer monsoon over the western North Pacific. J. Meteor. Soc. Japan, 80, 67-83, https://doi.org/10.2151/jmsj.80.67.

— , and B. Wang, 2000: Interannual variability of summer monsoon onset over the western North Pacific and the underlying processes. J. Climate, 13, 2483-2501, https://doi.org/10.1175/ 1520-0442(2000)013<2483:IVOSMO > 2.0.CO;2.

— and - 2001: Multi-stage onset of the summer monsoon over the western North Pacific. Climate Dyn., 17, 277-289, https://doi.org/10.1007/s003820000118.

Xie, A., Y. S. Chung, X. Liu, and Q. Ye, 1998: The interannual variations of the summer monsoon onset over the South China Sea. Theor. Appl. Climatol., 59, 201-213, https://doi.org/ 10.1007/s007040050024.

Xu, K., and R. Lu, 2015: Break of the western North Pacific summer monsoon in early August. J. Climate, 28, 3420-3434, https://doi.org/10.1175/JCLI-D-14-00588.1.

- , and 2016: Change in tropical cyclone activity during the break of the western North Pacific summer monsoon in early August. J. Climate, 29, 2457-2469, https://doi.org/10.1175/ JCLI-D-15-0587.1.

— , and - 2018: Decadal change of the western North Pacific summer monsoon break around 2002/03. J. Climate, 31, 177-193, https://doi.org/10.1175/JCLI-D-16-0739.1.

Yan, J. Y., 1997: Climatological characteristics on the onset of the South China Sea southwest monsoon. Acta Meteor. Sin., 55, 174-186. 
Yasunari, T., 1979: Cloudiness fluctuations associated with the Northern Hemisphere summer monsoon. J. Meteor. Soc. Japan, 57, 227-242, https://doi.org/10.2151/jmsj1965.57.3_ 227.

Yatagai, A., K. Kamiguchi, O. Arakawa, A. Hamada, N. Yasutomi, and A. Kitoh, 2012: APHRODITE: Constructing a longterm daily gridded precipitation dataset for Asia based on a dense network of rain gauges. Bull. Amer. Meteor. Soc., 93, 1401-1415, https://doi.org/10.1175/BAMS-D-1100122.1.

Zeng, X., and E. Lu, 2004: Globally unified monsoon onset and retreat indexes. J. Climate, 17, 2241-2248, https://doi.org/ 10.1175/1520-0442(2004)017<2241:GUMOAR > 2.0.CO;2.

Zhan, R., Y. Wang, and M. Ying, 2012: Seasonal forecasts of tropical cyclone activity over the western North Pacific: A review. Trop. Cyclone Res. Rev., 1, 307-324, https://doi.org/ 10.6057/2012TCRR03.07.
Zhang, H., 2010: Diagnosing Australia-Asian monsoon onset/ retreat using large-scale wind and moisture indices. Climate Dyn., 35, 601-618, https://doi.org/10.1007/s00382-009-0620-x.

Zhang, Q., Q. Liu, and L. Wu, 2009: Topical cyclone damages in China 1983-2006. Bull. Amer. Meteor. Soc., 90, 489-496, https://doi.org/10.1175/2008BAMS2631.1.

Zhang, W., F. F. Jin, J. Li, and H. L. Ren, 2011: Constrasting impacts of two-type El Niño over the western North Pacific during boreal autumn. J. Meteor. Soc. Japan, 89, 563-569, https://doi.org/10.2151/jmsj.2011-510.

Zhou, W., and J. C. L. Chan, 2007: ENSO and the South China Sea summer monsoon onset. Int. J. Climatol., 27, 157-167, https:// doi.org/10.1002/joc. 1380 .

Zong, H., and L. Wu, 2015: Re-examination of tropical cyclone formation in monsoon troughs over the western North Pacific. Adv. Atmos. Sci., 32, 924-934, https://doi.org/ 10.1007/s00376-014-4115-2. 